\title{
The added utility of nonlinear methods compared to linear methods in rescaling soil moisture products
}

DOI:

https://doi.org/10.1016/j.rse.2017.05.017

\section{Document Version}

Accepted author manuscript

Link to publication record in Manchester Research Explorer

\section{Citation for published version (APA):}

Afshar, M., \& Yilmaz, M. T. (2017). The added utility of nonlinear methods compared to linear methods in rescaling soil moisture products. Remote Sensing of Environment, 196, 224. https://doi.org/10.1016/j.rse.2017.05.017

\section{Published in:}

Remote Sensing of Environment

\section{Citing this paper}

Please note that where the full-text provided on Manchester Research Explorer is the Author Accepted Manuscript or Proof version this may differ from the final Published version. If citing, it is advised that you check and use the publisher's definitive version.

\section{General rights}

Copyright and moral rights for the publications made accessible in the Research Explorer are retained by the authors and/or other copyright owners and it is a condition of accessing publications that users recognise and abide by the legal requirements associated with these rights.

\section{Takedown policy}

If you believe that this document breaches copyright please refer to the University of Manchester's Takedown Procedures [http://man.ac.uk/04Y6Bo] or contact uml.scholarlycommunications@manchester.ac.uk providing relevant details, so we can investigate your claim.

\section{OPEN ACCESS}



METHODS IN RESCALING SOIL MOISTURE PRODUCTS

6 Civil Engineering Department, Middle East Technical University, Ankara, Turkey

$7 \quad$ * Correspondence to: M. T. Yilmaz, tuyilmaz@metu.edu.tr

$9 \quad$ April 22, 2017

\section{Abstract}

12 In this study, the added utility of nonlinear rescaling methods relative to linear methods in the 13 framework of creating a homogenous soil moisture time series has been explored. The 14 performances of 31 linear and nonlinear rescaling methods are evaluated by rescaling the Land

15 Parameter Retrieval Model (LPRM) soil moisture datasets to station-based watershed average 16 datasets obtained over four United States Department of Agriculture (USDA) Agricultural 17 Research Service (ARS) watersheds. The linear methods include first-order linear regression, 18 multiple linear regression, and multivariate adaptive regression splines (MARS), whereas the 19 nonlinear methods include cumulative distribution function matching (CDF), artificial neural 20 networks (ANN), support vector machines (SVM), Genetic Programming (GEN), and copula 21 methods. MARS, GEN, SVM, ANN, and the copula methods are also implemented to utilize

22 lagged observations to rescale the datasets. The results of a total of 31 different methods show that 23 the nonlinear methods improve the correlation and error statistics of the rescaled product compared 
24 to the linear methods. In general, the method that yielded the best results using training data 25 improved the validation correlations, on average, by 0.063, whereas ELMAN ANN and GEN, 26 using lagged observations methods, yielded correlation improvements of 0.052 and 0.048 , 27 respectively. The lagged observations improved the correlations when they were incorporated into rescaling equations in linear and nonlinear fashions, with the nonlinear methods (particularly SVM and GEN but not ANN and copula) benefitting from these lagged observations more than the linear methods. The overall results show that a large majority of the similarities between the LPRM and watershed average datasets are due to linear relations; however, nonlinear relations clearly exist,

32 and the use of nonlinear rescaling methods clearly improves the accuracy of the rescaled product.

Key Words: Soil moisture, rescaling, linear, nonlinear, remote sensing

\section{Introduction}

Soil moisture is one of the key variables in many geophysical science applications (e.g.,

37 those dealing with climate, hydrology, water resources, or agriculture; Lawrence \& Hornberger, 2007) owing to its memory (Han et al., 2014) and role in water and energy exchange between land and the atmosphere (Koster et al., 2004). Hence, an accurate estimation of soil moisture is critical for many applications (Dorigo et al., 2012). Different soil moisture time series for the same

41 location and same time period can be retrieved via different platforms (e.g., hydrological models,

42 in situ observations, and remote sensing). It is often desirable to merge these different datasets to 43 obtain more accurate estimates (Anderson et al., 2012; Yilmaz et al., 2012). However, due to the 44 limitations of these platforms (e.g., satellites can monitor only the top few centimeters at relatively coarse resolutions, points in in situ observations have spatial representativeness limitations, and models have different parameterizations (Koster et al., 2009)), these datasets have systematic 
47 differences in their horizontal, temporal, and/or vertical supports (Dirmeyer et al., 2004; Koster et 48 al., 2009). As a result, soil moisture values obtained from various platforms often need to be rescaled before they can be meaningfully validated, merged, or used in different applications

50 (Dirmeyer et al., 2004; Reichle \& Koster, 2005; Reichle et al., 2008; Yilmaz and Crow, 2013; Yin 51 et al., 2014; Su and Ryu, 2015).

Many different methods are proposed to handle these systematic differences between soil moisture products, where an unscaled original product $Y$ is rescaled to the space of a reference

54 product X. However, the performances of these methods depend on many factors, including sampling errors, the degree to which the rescaling methods' underlying assumptions are met, and the goal of the rescaling efforts. Examples of such goals include minimizing the variability of the difference between the rescaled product $\left(\mathrm{Y}^{*}\right)$ and $\mathrm{X}$ via a first-order linear regression (REG1), matching the total variability of a dataset $\mathrm{Y}$ to an arbitrary reference dataset $\mathrm{X}$ (VAR), matching

59 the cumulative distribution function (cdf), and matching only the signal variability of $\mathrm{Y}$ to that of $\mathrm{X}$ (here, "signal" refers to the true variability of a dataset, where the total variability is composed

61 of true signal variability and noise variability components) using triple collocation analysis (TCA:

62 Hain et al., 2011; Miralles et al., 2011; Parinussa et al., 2011; Scipal et al., 2008; Stoffelen, 1998;

63 Zwieback et al., 2012).

Once the rescaling method is selected for implementation in a specific application, this method can be implemented using different strategies (Yilmaz et al., 2016). For example, a dataset can be rescaled by using a single coefficient for the entire time series by using separate rescaling

67 coefficients for each month or separate coefficients for the anomaly and seasonality components.

68 Such rescaling strategies affect the accuracy statistics of $Y^{*}$, even though, by definition, a particular 
optimum method refers to the method that results in the best statistic of interest, among other

71 methods). To give a more specific example, consider the relative accuracies of $\mathrm{X}$ and $\mathrm{Y}$ or the

72 differences between the signal-variability-to-noise-variability ratio (Gruber et al., 2016), for X

$73\left(\mathrm{SNR}_{\mathrm{X}}\right)$ and $\mathrm{Y}\left(\mathrm{SNR}_{\mathrm{Y}}\right)$. In general, the relative variations of $\mathrm{SNR}_{\mathrm{X}}$ and $\mathrm{SNR}_{\mathrm{Y}}$ are expected to impact

74 the overall performance of the rescaling methods through the use of various rescaling strategies

75 (Yilmaz et al., 2016) for many applications (e.g., the creation of homogenous time series and data

76 assimilation). For example, if $\mathrm{SNR}_{\mathrm{X}} \gg \mathrm{SNR}_{\mathrm{Y}}$, it is better to rescale $\mathrm{Y}$ strongly to $\mathrm{X}$ (e.g., by

77 rescaling the seasonality and anomaly components separately using two different rescaling

78 coefficients or rescaling datasets for each month separately using 12 different rescaling

79 coefficients). By contrast, if $\mathrm{SNR}_{\mathrm{Y}}>\mathrm{SNR}_{\mathrm{X}}$, it is better to weakly rescale $\mathrm{Y}$ to $\mathrm{X}$ (e.g., by rescaling

80 the entire time series at once and using a single rescaling coefficient). Hence, the performance of

81 any rescaling method (e.g., REG1, VAR, TCA, and CDF) could vary depending on the

82 aggressiveness with which the rescaling strategy is implemented (e.g., weak or strong; Yilmaz et

83 al., 2016).

84 Both the rescaling method selection (Yilmaz \& Crow, 2013) and degree of aggressiveness

85 implemented (Yilmaz et al., 2016) can impact the optimality of the $\mathrm{Y}^{*}$ statistics. Here, the question

86 arises whether the inter-comparisons of rescaling methods make sense, without taking into

87 consideration SNR variations. Yilmaz et al. (2016) investigated the impact of SNR variations using

88 only a particular rescaling method (VAR). Hence, before making comments with high confidence,

89 a sensitivity study that comprehensively investigates the impact of SNR variations on the

90 performances of various rescaling methods is still required. However, in the absence of evidence,

91 it is viable that SNR variations will impact various rescaling methods similarly, though the actual

92 degree of improvement via stronger/weaker rescaling strategies may depend on the particular 
rescaling method. Accordingly, a universally optimum rescaling method that fits all applications may not exist; the optimality of a rescaling method is largely application specific, particularly if the underlying assumptions inherent to its own methodology are not met. Hence, studies investigating the relative performances of different rescaling methods (both linear and nonlinear) may still contribute to the efforts on the topic of optimal rescaling methods, even without explicitly considering SNR variations.

Satellite-based soil moisture data are often validated using station-based watershed average data (Jackson et al., 2010, 2012), which have considerably higher local nonlinearity, due to the soil moisture dynamics (Crow \& Wood, 2002). The spatial support difference between stationand remote sensing-based products (i.e., point vs areal average) is another source that introduces nonlinear relations between different products. In a recent study, Zwieback et al. (2016) introduced nonparametric $\mathrm{CDF}$ and used two new parametric methods to extend TCA to investigate the impact of nonlinear relations on the error statistics obtained via TCA. This study particularly stresses the existing quadratic relations (e.g., the saturation of sensitivity of a product with respect to the sensitivity of another product) between the actual signal components of different soil moisture products, which may lead to nonlinear relations. Zwieback et al. (2016) also provided an extensive discussion on the existence of nonlinear relations between soil moisture products. It is, therefore, viable that such existing nonlinear relations between datasets may not be captured using linear methods, and the use of nonlinear methods may be necessary. By contrast, the variety of nonlinear methods used to rescale soil moisture datasets remains very limited, and there is still more room to investigate the performance of such nonlinear methods.

Among the rescaling methods used in soil moisture studies, CDF (Drusch et al., 2005; Reichle \& Koster, 2004; Yin et al., 2015; Zwieback et al., 2016) has received particular attention. 
116

117

118

119

120

121

122

123

124

125

126

127

128

129

130

131

132

133

134

135

136

137

138

Other methods, based on VAR (Crow et al., 2005; Draper et al., 2009; Su et al., 2013), REG1 (Brocca et al., 2013; Crow \& Zhan, 2007; Crow, 2007;), TCA (Yilmaz \& Crow, 2013), quadratic polynomials (Zwieback et al., 2016), copula (Leroux et al., 2014), and Wavelets (Su \& Ryu, 2015) have also been implemented to reduce the systematic differences between soil moisture time series. However, a comprehensive intercomparison of the performances of these methods in a soil moisture rescaling study has not yet been performed.

The above-listed methodologies have been explicitly used in soil moisture rescaling studies, whereas many other methods have not. For example, multiple linear regressions using quadratic equations (REG2) and lagged observations (REGL) have previously been used in a soil moisture TCA framework (Crow et al., 2015; Su et al., 2014; Zwieback et al., 2016), but quadratic equations and lagged observations together (REGL2) have not. Among the many machine learning methodologies, ANN methods (Rochester et al., 1956) have been used to retrieve soil moisture via microwave measurements (Notarnicola et al., 2008; Paloscia et al., 2008; Prigent et al., 2005; Rodriguez et al., 2015) and SVM methods (Cortes \& Vapnik, 1995) have been used to predict soil moisture (Gill et al., 2006) in the root zone using data assimilation techniques (Liu et al., 2010). Other methods that can be used to relate the different datasets, such as the nonlinear regression methods GEN (Koza, 1994) and MARS (Friedman, 1991), have not been used in soil moisturerelated studies. To our knowledge, none of these methods (REG2, REGL, REGL2, MARS, GEN, SVM, and ANN) have previously been explicitly used to rescale soil moisture datasets.

The soil moisture has a high temporal memory (i.e., autocorrelation), and consecutively retrieved soil moisture observations have high dependence, implying that previously retrieved soil moisture observations could arguably be viewed as a slightly degraded version of the current values. This property is very valuable for satellite-based soil moisture retrievals; lagged soil 
moisture products could be used as independent observations, given that past observations are quasi-independently obtained from current observations. This dependence has been utilized by many recent studies (Crow et al., 2015; Su et al., 2014; Zwieback et al., 2013), particularly those focusing on soil moisture TCA methods, which require three independent products. Exploiting the same information source, lagged variables are inherently used by some ANN types in building robust relations between the input and output layers. Although many other methods (e.g., multiple linear regression, MARS, GEN, copula, and SVM) could also benefit from such information in the framework of rescaling soil moisture variables, such an effort has not been made to date.

VAR, REG1, TCA, and CDF have unique solutions and are widely implemented in soil moisture rescaling studies. The optimality of linear rescaling methods (VAR, REG1, and TCA) in the context of data assimilation has been investigated both analytically and numerically by Yilmaz and Crow (2014), and some remedies are available for these methods when the underlying assumptions are not met (Crow \& Yilmaz, 2014; Su et al., 2014). However, because the implementations of nonlinear rescaling methods remain limited in the context of rescaling soil moisture time series, the performance of these nonlinear methods, which are relative to that of linear methods, remains largely unexplored. Therefore, there is still room to investigate the performances of nonlinear methods relative to those of linear methods to better understand the degree of existing nonlinearity in soil moisture products, even though the degree of existing nonlinearity and degree to which these nonlinear relations can be captured drives the actual difference between the performance of the nonlinear and linear rescaling methodologies.

This study is the first to use a number of methods (REG2, REGL, REGL2, ANN, SVM, GEN, and MARS) and their lagged types to explicitly rescale the soil moisture observations. This study also includes the first comprehensive comparison of the performances of linear methods 
162 (REG1, REG2, REGL, REGL2, VAR, TCA, and MARS) as well as nonlinear methods (CDF, 163 copula, ANN, SVM, and GEN) in rescaling soil moisture datasets. Through these 164 intercomparisons, this study comprehensively analyzes the added utility of lagged observations in 165 a soil moisture rescaling framework. This study is particularly relevant for the efforts to create a 166 homogenous time series in the framework of global soil moisture dataset validation (Leroux et al., 167 2014) and trend analysis (Dorigo et al., 2012), contributes to the efforts to better understand the 168 optimality of different rescaling methodologies (Yilmaz and Crow, 2013; Yilmaz et al., 2016), and 169 adds to the efforts to identify the degree of the existing nonlinearity in soil moisture products.

170

\section{2. Linear and Nonlinear Rescaling Methods}

\section{2.1. Linear Regression}

\section{$173 \quad$ 2.1.1 First-order Linear Regression}

Linear rescaling methods have been widely used to rescale soil moisture time series to

175 reduce their inconsistency (Brocca et al., 2013; Crow et al., 2005; Crow \& Zhan, 2007). Overall,

176 linear rescaling methods are implemented by considering the most general linear relation between

177 a reference dataset (X) and an original unscaled dataset (Y) in the form of:

$178 \quad \mathrm{Y}^{*}=\mu_{\mathrm{X}}+\left(\mathrm{Y}-\mu_{\mathrm{Y}}\right) \mathrm{c}_{\mathrm{Y}}$

179 where $\mathrm{Y}^{*}$ is the rescaled version of $\mathrm{Y} ; \mu_{\mathrm{X}}$ and $\mu_{\mathrm{Y}}$ are time averages of $\mathrm{X}$ and $\mathrm{Y}$, respectively; and $c_{\mathrm{Y}}$ 180 is a scalar rescaling factor (in this study, minimum-maximum fits are not considered). Here, $\mathrm{c}_{\mathrm{Y}}$ is 181 found using REG1, VAR, and TCA-based linear methods (Yilmaz and Crow, 2013):

$182 \quad c_{Y}^{R}=\rho_{X Y} \sigma_{X} / \sigma_{Y}$

$183 \quad c_{Y}^{\mathrm{V}}=\sigma_{\mathrm{X}} / \sigma_{\mathrm{Y}}$

$184 \quad \mathrm{c}_{\mathrm{Y}}^{\mathrm{T}}=\Sigma_{\mathrm{xz}} / \Sigma_{\mathrm{yz}}$. 
185 where $\mathrm{Z}$ is a third product that is similar to products $\mathrm{X}$ and $\mathrm{Y} ; \Sigma_{\mathrm{xz}}$ and $\Sigma_{\mathrm{yz}}$ are covariances between $186 \quad \mathrm{X}-\mathrm{Z}$ and $\mathrm{Y}-\mathrm{Z}$, respectively; $\mathrm{c}_{\mathrm{Y}}^{\mathrm{R}}, \mathrm{c}_{\mathrm{Y}}^{\mathrm{V}}$, and $\mathrm{c}_{\mathrm{Y}}^{\mathrm{T}}$ are the linear rescaling factors for the REG1-, VAR-, 187 and TCA-based methods, respectively; $\sigma_{\mathrm{X}}$ and $\sigma_{\mathrm{Y}}$ are the standard deviations of $\mathrm{X}$ and $188 \mathrm{Y}$, respectively; and $\rho_{\mathrm{XY}}$ is the correlation coefficient between $\mathrm{X}$ and $\mathrm{Y}$. Accordingly, the rescaled 189 products are estimated as

$190 \quad \mathrm{Y}_{\mathrm{REG} 1}^{*}=\mu_{\mathrm{X}}+\left(\mathrm{Y}-\mu_{\mathrm{Y}}\right) \mathrm{c}_{\mathrm{Y}}^{\mathrm{R}}$

$191 \quad \mathrm{Y}_{\mathrm{VAR}}^{*}=\mu_{\mathrm{X}}+\left(\mathrm{Y}-\mu_{\mathrm{Y}}\right) \mathrm{c}_{\mathrm{Y}}^{\mathrm{V}}$

$192 \quad \mathrm{Y}_{\mathrm{TCA}}^{*}=\mu_{\mathrm{X}}+\left(\mathrm{Y}-\mu_{\mathrm{Y}}\right) \mathrm{c}_{\mathrm{Y}}^{\mathrm{T}}$,

193 where $\mathrm{Y}_{\mathrm{REG} 1}^{*}, \mathrm{Y}_{\mathrm{VAR}}^{*}$, and $\mathrm{Y}_{\mathrm{TCA}}^{*}$ are the rescaled products using REG1, VAR, and TCA methods, 194 respectively.

\subsubsection{Multiple Linear Regression}

Above, the most general linear form (equation 1) is used to represent the relation between 198 soil moisture products. The added utility of quadratic equations (Zwieback et al., 2016) and lagged 199 variables (Su et al., 2014) have been recently investigated in the TCA framework. In this study, 200 three multiple linear regression equations that take advantage of quadratic equations and lagged 201 observations are considered:

$202 \quad \mathrm{Y}_{\mathrm{REG} 2}^{*}=\mu_{\mathrm{X}}+\left(\mathrm{Y}-\mu_{\mathrm{Y}}\right) \mathrm{c}_{\mathrm{Y} 1}+\left(\mathrm{Y}-\mu_{\mathrm{Y}}\right)^{2} \mathrm{c}_{\mathrm{Y} 2}$,

$203 \quad \mathrm{Y}_{\mathrm{REGL}}^{*}=\mu_{\mathrm{X}}+\left(\mathrm{Y}_{\mathrm{t}}-\mu_{\mathrm{Y}}\right) \mathrm{c}_{\mathrm{Y} 3}+\left(\mathrm{Y}_{\mathrm{t}-1}-\mu_{\mathrm{Y}}\right) \mathrm{c}_{\mathrm{Y} 4}$

$204 \quad \mathrm{Y}_{\mathrm{REGL} 2 \mathrm{t}}^{*}=\mu_{\mathrm{X}}+\left(\mathrm{Y}_{\mathrm{t}}-\mu_{\mathrm{Y}}\right) \mathrm{c}_{\mathrm{Y} 5}+\left(\mathrm{Y}_{\mathrm{t}-1}-\mu_{\mathrm{Y}}\right) \mathrm{c}_{\mathrm{Y} 6}+\left(\mathrm{Y}_{\mathrm{t}}-\mu_{\mathrm{Y}}\right)^{2} \mathrm{c}_{\mathrm{Y} 7}$,

205 where $t$ is the time step; $Y_{t-1}$ is the lagged version of $Y_{t} ; Y_{R E G 2}^{*}, Y_{R E G L}^{*}$, and $Y_{R E G L 2}^{*}$ are the rescaled 206 products obtained using second order linear regression, lagged linear regression, and second 207 order/lagged linear regression, respectively. In this study, only higher than second order linear 
regressions are not used because Zwieback et al. (2016) used second order relations, and our

209 independent analysis also shows that second order relations yield the best results using independent

210 validation data (results not shown). Here, even though the quadratic terms are nonlinear in the

211 explanatory variable, in this study, they are investigated under the linear category as their

212 regression parameters (intercept, slope, and quadratic coefficient) are linear. However, it is

213 stressed that this choice is inconsequential and impacts neither the results nor the conclusions.

214

$215 \quad$ 2.1.3 Multivariate adaptive regression splines

216

MARS (Friedman, 1991) is an extension of the linear regression method that handles

nonlinearities and the dependence between datasets. The MARS algorithm partitions training

218 datasets into splines (i.e., sections) with different slopes, and these splines are later smoothly

219 connected to each other into basis functions (i.e., polynomials). Here, the role of these basic

220 functions is to project $\mathrm{Y}$ (unscaled product) to a new variable $\mathrm{H}$ by considering a knot value (an

221 inflection point) and hinge functions that are automatically determined by the data (Hastie et al.,

222 2009).

The MARS algorithm consists of two phases of forward and backward stepwise

224 procedures. In the forward stepwise procedure, the model aims to find basis functions that reduce

225 the errors between the rescaled and reference variables the most. However, at the end of the

226 forward phase, the algorithm produces a complex model that gives a poor response for predicting

227 new independent data (Andres et al., 2011). In other words, the developed model in the forward

228 phase will overfit with the training data and therefore require a backward stepwise selection to

229 eliminate ineffective basis functions. The backward phase, in fact, prunes the model to create a 
231 and simple model (i.e., the mean of the reference dataset) in the forward phase and moves forward

232 by adding basis functions (i.e., polynomial) to the model. The least effective basis functions in the mean square sense are later eliminated, until the change in prediction error is small.

In this study, the training procedure, including the application of forward and backward 235 steps and the locating of knot points, is conducted by using earth package (Milborrow, 2016) in 236 the R environment (a freely available data analysis programming language; R Core Team, 2015). For more details about the MARS and its development procedure see studies of Hastie et al. (2009) 238 and Sharda et al. (2008).

\subsection{Nonlinear Rescaling Methods}

\subsubsection{Artificial Neural Networks}

ANNs, which are originally modeled from the existing information processing paradigm establish relations between datasets (e.g., X and Y) through networks of neurons (nodes) in the socalled hidden layers. There are different types of ANNs available in the literature, and they can be

246 classified with respect to their structure (i.e., numbers of layers and the way in which their neurons 247 are connected), training method, and activation function.

The structure of ANNs can be defined depending on the nature of the problem and datasets.

249 Strictly linear systems do not require any hidden layer, while the use of one or two hidden layers 250 is sufficient to solve most (if not all) complex nonlinear problems. However, the optimality of the 251 number of neurons has been an ongoing debate for almost two decades (Huang \& Babri, 1998; 252 Kentel, 2009; Murata et al., 1994; Sheela \& Deepa, 2013; Xu and Chen, 2008) and is not as clear 253 as the optimality of the hidden layer number. 
255 basis function (RBF; Poggio \& Girosi, 1990), ELMAN (Elman, 1990), and JORDAN (Jordan,

256 1997)] with different structures that belong to feed-forward, radial basis function, and recurrent

257 networks, are used to rescale the dataset(s) to the scale of a reference dataset. The optimum number

258 of hidden layers and neurons for each function are separately identified through a grid search

259 within a domain of (1-2) and (1-40) for the number of hidden layers and their neurons, respectively.

260 ANN implementations in this study have been carried out using the RSNNS package, which was

261 written by Bergmeir and Benitez (2012) for the R environment ( $\mathrm{R}$ Core Team, 2015). The

262 structural properties of the ANN functions (e.g., training method, activation functions) are chosen

263 by following the default values and guideline of the RSNNS package given in Table 1. For more

264 details about the networks used in this study and the differences in their parameters, readers can

265 refer to the user manual of the RSNNS package (Bergmeir \& Benitez, 2012).

$267 \quad$ 2.2.2 Genetic Programming

GEN (Koza, 1994; Vladislavleva et al., 2009) is an automatic programming technique that

269 is based on Darwin's theory of population evolution (abandoning poor members of society and

270 creating modified children selectively). GEN uses the Genetic Algorithm (GA) to create tree-

271 structured computer programs as a solution for defined problems (e.g., rescaling unscaled variables

272 to the reference space).

273 Given the availability of relevant datasets, GEN discovers their relationship through 274 randomly created computer programs that are composed of mathematical functions and arithmetic 275 operators without having a priori information about the datasets or their structures. GEN utilizes 276 these functions and picks the best-fitted ones (i.e., refines these functions) in a statistical sense by 
277 exchanging information through so-called crossover and mutation operators. Here, the crossover

278 operator combines randomly selected parts of two programs and creates a new program for the

279 new population, while the mutation operator creates a new program by randomly selecting one

280 part of a program and randomly mutating it. This refining process evolves over a series of

281 generations until reaching the termination criteria (e.g., evolving time, maximum generations,

282 error threshold, etc.).

283

All of the steps of GEN in this study are performed by using the RGP package (Flasch et

284 al., 2014) in the R language programming environment. The preliminary required parameters of

285 GEN (e.g., the causality relationship between unscaled and reference soil moisture products,

286 termination criteria, etc.) are presented in Table 2. The remaining required parameters (e.g., GA

287 operator's probabilities and performing procedure of them) are defined as per their default values

288 following the guidelines of the RGP package (Flasch et al., 2014).

289

290

\subsubsection{Support Vector Machine}

SVM (Vapnik \& Chervonenkis., 1974; Vapnik, 1998) is a statistic-based technique for

292 general (nonlinear) classification and regression. The SVM seeks to find the optimal function (as

293 flat as possible) with a margin that contains all points, with an error smaller than $\epsilon$ (Hernandez et

294 al., 2009). This flat linear function can be found by using an $\epsilon$-insensitive loss function that

295 penalizes errors greater than $\epsilon$, while the trade-off between flatness and precision is determined by

296 the regularization constant, "C", in an optimization problem as:

$297 \min _{\alpha, \alpha^{*}}\left[\frac{1}{2}\left(\alpha-\alpha^{*}\right)^{\mathrm{T}} \mathrm{Q}\left(\alpha-\alpha^{*}\right)+\epsilon \sum_{\mathrm{i}=1}^{\mathrm{l}}\left(\alpha_{\mathrm{i}}+\alpha_{\mathrm{i}}^{*}\right)+\sum_{\mathrm{i}=1}^{\mathrm{l}} \mathrm{y}_{\mathrm{i}}\left(\alpha_{\mathrm{i}}-\alpha_{\mathrm{i}}^{*}\right)\right]$,

298 subject to 
300

301

302

303

304

305

306

307

308

309

310

311

312

313

314

315

316

317

318

319

320 where $\left(\alpha_{i}, \alpha_{i}{ }^{*}\right)$ are Lagrange multipliers, $\mathrm{C}$ is the upper bound, $\mathrm{Q}$ is a 1 by 1 positive semi definite matrix, $Q_{i j} \equiv x_{i} x_{j} K\left(y_{i}, y_{j}\right)$, and $K\left(y_{i}, y_{j}\right)$ is the kernel function associated with the support vectors of $\left(y_{i}, y_{j}\right)$. The nonlinear kernel function transforms datasets into a higher dimensional feature space, where the optimized linear function in the new feature space is equal to a nonlinear regression in the original space (Olson \& Delen, 2008).

Here, the optimization of $\epsilon, C$, and $\gamma$ (parameter of kernel function) in the above equations is essential for obtaining the best regression function (Smola \& Scholkopf, 2004). Therefore, once the radial basis kernel function is selected, an optimization procedure is implemented for the $\epsilon, \mathrm{C}$, and $\gamma$ hyper parameters based on cross validation (the optimized values are not shown). The domains of the parameters that need to be optimized are $0.01-1,1-1000$, and $0.5-1$ for the $\epsilon, \mathrm{C}$, and $\gamma$ parameters, respectively (Hernandez et al., 2009; Meyer et al., 2015). In this study, the above calculations of the regression functions are performed by using the e1071 R package (Meyer et al., 2015) in the R environment. For more details about the SVM and its development procedure, see the studies by Vapnik (1998) and Smola and Scholkopf (2004), and for the e1071 R package, see the study by Meyer et al. (2015).

\subsubsection{Cumulative Distribution Function Matching}

The CDF (Reichle \& Koster, 2004) is among the earliest implemented techniques that aim to reduce the systematic differences between soil moisture datasets by the matching the cdf of the datasets. This method has been widely used in many applications, particularly in studies that focus on data assimilation (Drusch, 2007; Li et al., 2010). CDF aims to match the rankings (i.e., cdf) of 
321 a soil moisture dataset to those of a selected reference dataset. The schematic representation of the

322 CDF used in this study is given in Figure 1 (i.e., the path shown by the panels BADE). For more

323 details, please see the study by Reichle and Koster (2004).

324

325

\subsubsection{Copula}

Copula functions are widely used to describe the multivariate dependence between random variables by using their univariate distributions. More specifically, this method enables the

328 estimation of a multivariate cdf of random variables by using copula functions that utilize the 329 univariate cdf of random variables, assuming the marginal probability distributions follow a 330 uniform distribution. The general equation for the estimation of the multivariate distribution in the 331 copula approach is described by Sklar (1959) as follows:

$\mathrm{C}\left(\mathrm{cdf}_{\mathrm{u}_{1}}, \mathrm{cdf}_{\mathrm{u}_{2}}, \ldots, \mathrm{cdf}_{\mathrm{u}_{\mathrm{N}}}\right)=\operatorname{Pr}\left(\mathrm{U}_{1} \leq \mathrm{u}_{1}, \mathrm{U}_{2} \leq \mathrm{u}_{2}, \ldots, \mathrm{U}_{\mathrm{N}} \leq \mathrm{u}_{\mathrm{N}}\right)$

Where $\mathrm{C}$ is a unique multivariate copula function that contains all of the dependence information among the datasets through a single parameter (e.g., P or $\theta$ ). Here, Sklar's theorem implies that for any group of random variables $U_{1}, U_{2}, \ldots, U_{N-1}$, there exists a copula function $\mathrm{C}\left(\mathrm{cdf}_{\mathrm{u}_{1}}, \mathrm{cdf}_{\mathrm{u}_{2}}, \ldots, \mathrm{cdf}_{\mathrm{u}_{\mathrm{N}}}\right)$ that links these variables through an estimation of the multivariate

337 probability distribution of these random variables.

to a rescaling problem, which can be found via the partial derivative of the copula functions in the

340 following form:

$341 \quad \mathrm{C}_{\mathrm{U}_{\mathrm{N}} \mid \mathrm{U}_{1}, \mathrm{U}_{2}, \ldots, \mathrm{U}_{\mathrm{N}-1}}=\frac{\partial \mathrm{C}\left(\mathrm{cdf}_{\mathrm{u}_{1},}, \mathrm{cdf}_{\left.\mathrm{u}_{2}, \ldots, \mathrm{cdf}_{\mathrm{u}_{\mathrm{N}}}\right)} \partial \mathrm{C}\left(\mathrm{cdf}_{\mathrm{u}_{1},}, \mathrm{cdf}_{\left.\mathrm{u}_{2}, \ldots, \mathrm{cdf}_{\mathrm{u}_{\mathrm{N}-1}}\right)}\right.\right.}{\text {. }}$

342 Here, the goal is to first estimate $\operatorname{cdf}_{u_{N}}$ and to then retrieve the value of $U_{N}$ by utilizing the cdf of 343 the observed variables $\left(U_{1}, U_{2}, \ldots, U_{N-1}\right)$. Here, these observed variables could be selected as 
344 observations from different platforms as well as lagged values of the same variable to be predicted.

345 However, the solution of equation 14 requires knowledge of the conditional cdf of the observed

346 variables $\left(\mathrm{cdf}_{\mathrm{U}_{\mathrm{N}} \mid \mathrm{U}_{1}, \mathrm{U}_{2}, \ldots, \mathrm{U}_{\mathrm{N}-1}}\right)$, which can be found through an iterative procedure (for details on

347 this optimal solution, see the study of Leroux et al., 2014).

348 The schematic representation of the CDF and copula methods that rescale the variable Y to

$349 \mathrm{X}$ is shown in Figure 1. In this example, the conditional cdf of 0.47 gives the optimal copula result

350 (panel C in Figure 1), which has a curved shape compared to the projection line of the cdf (straight

351 line in panel A). The optimal shape and location of this projection line curvature in panel $\mathrm{C}$ can be

352 found by optimizing the parameters $\mathrm{P}, \theta$, and/or conditional cdf value, whereas the optimality 353 depends on the goal of the application.

354 The list of copula functions used in this study [five total: NORMAL (Frahm et al., 2003),

355 CLAYTON (Clayton, 1978), GUMBEL (Gumbel, 1960), FRANK (Genest, 1987), and JOE (Joe,

356 1997)] and their properties are given in Table 3. In this study, all of the steps, including the

357 calculation of the CDFs and the fitting of different copulas, are performed using the $\mathrm{R}$ 358 programming language package "Copula", which was written by Hofert et al. (2012). For more 359 information about the mathematical properties of the copula function and families, fitting 360 procedures, and simulation issues, see the studies by Genest and Favre (2004) and Nelsen (2013).

\subsubsection{Lagged Types}

Soil moisture is a highly autocorrelated variable; accordingly, any given day’s soil moisture

364 observations contain valuable information about the next day's actual soil moisture values. This

365 implies that is it is viable to use lagged observations as independent observations (Crow et al., 366 2015; Su et al., 2014) in addition to non-lagged observations (i.e., two input time series are used 
to predict a single output time series). Among the rescaling methods used in this study, the performances of the lagged versions of MARS (MARSL), GEN (GENL), SVM (SVML), MLP (MLPL), RBF (RBFL), ELMAN (ELMANL), JORDAN (JORDANL), NORMAL (NORMALL), CLAYTON (CLAYTONL), GUMBEL (GUMBELL), FRANK (FRANKL), and JOE (JOEL) are also evaluated in addition to their non-lagged types.

\subsection{Comparison of the Rescaling Methods}

In this study, the rescaling methods are compared for their ability to minimize the error variance of $Y^{*}\left(\sigma_{\epsilon_{Y^{*}}}^{2}\right)$, minimize the error absolute mean bias (AMB), and maximize the $\rho$ between $\mathrm{X}$ and $\mathrm{Y}^{*}\left(\rho_{\mathrm{XY}}\right)$. The details of these statistics are given below in chapter 4 . Here, $\rho_{\mathrm{XY}}$ and $\rho_{\mathrm{XY}}$ are the same for all linear rescaling methods. Among the linear methods, by definition, REGL2 minimizes the $\sigma_{\epsilon_{Y^{*}}}^{2}$ of the training data; hence, REGL2 is preferable over other linear methods (REG1, REG2, REGL, VAR, and TCA) if $\sigma_{\epsilon_{Y^{*}}}^{2}$ is the selection criterion when the training and validation datasets are the same. Accordingly, the comparison of linear methods may not be meaningful given that REGL2 yields the minimum $\sigma_{\epsilon_{Y^{*}}}^{2}$, whereas all of the methods have an identical $\rho_{\mathrm{XY}^{*}}$ (if REGL3 was used, it would have further reduced the training $\sigma_{\epsilon_{Y^{*}}}^{2}$ ). By contrast, the optimality of REGL2 is not guaranteed when the parameters obtained using the training datasets are applied to independent validation datasets. This implies that the inter-comparison of linear methods for the validation of $\mathrm{Y}^{*}$ is still necessary before confidently making conclusions about their performances.

Linear and nonlinear methods have particular advantages and disadvantages, which impact their optimality for different applications and goals. Among the linear methods, REGL2 minimizes the mean square difference between $\mathrm{X}$ and $\mathrm{Y}^{*}$, VAR matches the total variability components of $\mathrm{X}$ 
and $\mathrm{Y}$, and TCA matches the signal variability components of $\mathrm{Y}$ and $\mathrm{X}$ so that the error variance of the analysis in data assimilation framework is minimized (Yilmaz \& Crow, 2013). Accordingly, the applications that aim to linearly create a homogenous dataset for which $\mathrm{Y}^{*}$ is closest to $\mathrm{X}$ (i.e., those that seek to minimize mean square errors) may prefer REGL2 (assuming that REGL2 does not severely overfit the datasets). MARS is expected to yield better results than the other linear methods (due to their advantage of the use of splines at different knot points), but this expectation may not be analytically proven because REG2 and REGL2 take advantage of quadratic relations. Given that merging-type studies (e.g., data assimilation) explicitly require the signal variability components of $\mathrm{Y}^{*}$ and $\mathrm{X}$ to be the same, TCA is a better candidate for such studies (Yilmaz \& Crow, 2013). Among the nonlinear rescaling methods, copula links the $\mathrm{CDF}_{\mathrm{X}}$ and $\mathrm{CDF}_{\mathrm{Y}}$ multivariate functions instead of matching them, similar to CDF (Figure 1). By contrast, ANN, GEN, and SVM machine-learning methods establish the relationships between datasets and act like a system in which the input-output relations may be too complex to be shown explicitly with equations or perhaps cannot be shown at all. When ANN and GEN are compared, GEN has an advantage: first, the assembly of blocks (i.e., the input variables, target, and mathematical functions) is defined, and then, the optimized structure of the model and its coefficients are determined during the training process. By contrast, in ANNs, the structure of the network is specified first and the coefficients are then obtained during the training process. Conversely, the main drawback of GEN is its high computational cost due to the infinite search space of symbolic expressions.

Overall, the relative performances of methods using independent datasets that are not used in their parameter estimation are not analytically predictable (including the linear methods). Hence, it may not be possible to analytically prove that any particular rescaling method will result 
413 in a superior accuracy by using independent validation data. Accordingly, a comparison of the

414 performances of linear and nonlinear methods is still needed to attain a greater understanding of

415 their relative added utility.

416 Many of the methods discussed here (ANN, GEN, SVM, and copula) have different

417 structures and therefore different complexities. However, currently, these methods can be easily

418 implemented in various applications using data analysis programming languages, such as $\mathrm{R}$,

419 Matlab, IDL, and Python. The available packages or toolboxes in these programming languages

420 train the networks (e.g., optimize the weights of connections among the neurons of layers of the

421 network) such that the considered performance statistics between the reference and predicted

422 values are optimized. These packages require users only to define certain parameters (e.g., the

423 number of hidden layers and neurons and type of functions that ANNs have to implement, such as

424 learning, update, activation, and output functions; Table 2). Despite the fact that these methods

425 have greater computational complexity (i.e., much longer codes running in the background) than

426 other simpler rescaling methods (e.g., linear methods and CDF), these complex methods can be

427 implemented using a couple of lines of codes that run for a very short time, similar to less-complex

428 methods, once the optimized parameter sets are obtained (this optimization phase of these complex

429 methods could require relatively longer computational times). Hence, there is relatively very little

430 difference between the simpler methods (e.g., linear methods) and the more complex methods

431 (e.g., machine learning methods), especially in terms of the computational ease of implementing

432 these rescaling methods, except for the optimization of components. 


\section{Datasets}

The remote sensing-based Land Parameter Retrieval Method (LPRM) soil moisture datasets (Owe et al., 2001, 2008) used in this study utilizes the Advanced Microwave Scanning Radiometer - Earth Observing System (AMSR-E) X-band and C-band observations. These datasets are acquired between 2002 and 2009 from the Vrije Universiteit Amsterdam (personal communication with Robert Parinussa, 2013). LPRM uses three parameters (soil moisture, vegetation water content, and soil or canopy temperature) as well as passive-microwave-based, dual-polarized (either 6.925 or $10.65 \mathrm{GHz}$ ) observations from AMSR-E for the retrieval of both the surface soil moisture and vegetation water content. The final LPRM soil moisture dataset is gridded to a spatial resolution of $0.25^{\circ}$ and has a daily temporal resolution with a revisit time of $\sim 3$ day. AMSR-E stopped transmitting data in October 2011 due to antenna problems, and the continuation of LPRM datasets will use observations retrieved from other sensors, such as the Advanced Microwave Scanning Radiometer-2 (Parinussa et al., 2015) and Fengyun-3B (Parinussa et al., 2014). For more details on the LPRM retrieval method, please see the studies by Owe et al. (2001, 2008).

The watershed average in situ soil moisture datasets are obtained for the LPRM local overpass time over the four USDA ARS watersheds: Little River (LR), Little Washita (LW), Walnut Gulch (WG), and Reynolds Creek (RC). These four watersheds contain dense soil moisture sensors (each watershed contains 16 to 29 stations over a 150 to $610 \mathrm{~km}^{2}$ area, less than a single LPRM pixel area) that make soil moisture measurements at depths from 0 to $5 \mathrm{~cm}$ and at intervals of 20 to 60 min over forest, grazing land, semiarid, and mountainous climatic regions. The areas of these watersheds are smaller than one LPRM pixel area. Soil moisture measurements at different stations are averaged to obtain a time series that is representative of each watershed (Jackson et 
457 al., 2010). Verification of these watershed average datasets has been performed via comparisons 458 against gravimetric soil moisture observations (Cosh et al., 2006, 2008). These datasets were 459 previously used to validate AMSR-E and Soil Moisture and Ocean Salinity (SMOS) surface soil 460 moisture products (Jackson et al., 2010, 2012). Watershed average datasets are acquired through 461 the International Soil Moisture Network (ISMN; Dorigo et al., 2011). Given that these datasets are 462 available only between June 2002 and July 2009 from the ISMN database, this study is limited 463 between these dates, even though the LPRM dataset is available beyond 2009. Among the 464 available data between these dates, there are 0 soil moisture values for 131,2 , and 52 days, for 465 LW, WG, and RC, respectively; these 0 values are assumed to be missing and are not used in the 466 analyses performed in this study.

467 Among the linear methods, TCA requires the use of a third product (along with the 468 watershed average and LPRM datasets) to estimate the rescaling coefficient (Stoffelen, 1998). For 469 this purpose, Noah land surface model version 2.7 (Ek et al., 2003) simulations obtained from 470 Global Land Data Assimilation System (GLDAS) simulations (Rodell et al., 2004) are used as the

471 third product in the TCA calculations. NOAH soil moisture simulations representing the top 10 $472 \mathrm{~cm}$ from four USDA ARS watersheds are retrieved at a spatial resolution of $0.25^{\circ}$ for the LPRM 473 local overpass time. These datasets are obtained from the Goddard Earth Sciences Data and 474 Information System (http://hydro1.sci.gsfc.nasa.gov/dods/). For more information about the 475 dataset, see the study by Rodell et al. (2004).

\section{Added Utility of Rescaling Methods}

In this study, the LPRM soil moisture values are rescaled to watershed average datasets

479 using linear (VAR, TCA, REG1, REG2, REGL, REGL2 and MARS) and nonlinear (CDF, GEN, 
SVM, ANN, and copula) methods, where ANN has four types (MLP, RBF, ELMAN, and

481

482

483

484

485

486

487 independent watershed average validation datasets and the statistics below:

488

$\varepsilon_{\mathrm{i}}=\mathrm{Sta}_{\mathrm{i}}-\mathrm{LPRM}_{\mathrm{i}}^{*}$

$489 \quad \mathrm{AMB}_{\mathrm{i}}=\left|\mu_{\varepsilon_{\mathrm{i}}}\right|$

490

$\sigma_{\varepsilon_{\mathrm{i}}}=\sqrt{\sum\left(\varepsilon_{\mathrm{i}}-\mu_{\varepsilon_{\mathrm{i}}}\right)^{2} /(\mathrm{n}-1)}$

$491 \quad \rho_{\mathrm{i}}=\frac{\Sigma_{\mathrm{Sta}_{\mathrm{i}} \mathrm{LPRM}_{\mathrm{i}}^{*}}}{\sigma_{\mathrm{Sta}_{\mathrm{i}}} \sigma_{\mathrm{LPRM}_{\mathrm{i}}}}$

where subscript $i$ indicates each watershed (total four), Sta is the station-based watershed average dataset, $\varepsilon$ is the error of $\mathrm{LPRM}^{*}$, and $\mu_{\varepsilon}$ and $\sigma_{\varepsilon}$ indicate the temporal mean and standard deviation 494 of the errors, respectively, AMB indicates the error absolute mean bias, $\mathrm{n}$ is the number of available observations, and $\sum()$ is the summation operator. The statistics $\rho, \sigma_{\varepsilon}$, and AMB are calculated over four watersheds separately.

Only mutually available LPRM and watershed average datasets are used to calculate all of

498 the statistics (equations 16-18) in this study. The datasets are divided into training and validation 499 parts. Some rescaling methods that are explicitly used in the autocorrelation information to rescale, 500 traini and validate datasets cannot be selected via random sampling; accordingly, temporally 501 continuous data are selected for training and validation. To reduce the impact of sampling errors 
on the results, two separate experiments are implemented: the first experiment uses the first (timewise) $25 \%$ of the data for validation and the remaining $75 \%$ for training, whereas the second experiment uses the first $75 \%$ for training and the remaining $25 \%$ for validation. Later, the statistics (equation 16-18) for these two experiments are averaged, and these averages are presented in this study.

The added utility $(\mathrm{U})$ of the rescaling methods is calculated with respect to the performance of the REG1 method:

$\mathrm{U}_{\mathrm{m}, \mathrm{s}, \mathrm{l}}=\mathrm{M}_{\mathrm{m}, \mathrm{s}, \mathrm{l}}-\mathrm{REG}_{\mathrm{s}, \mathrm{l}}$

where m represents 9 methods (listed below), s represents 4 locations (LR, LW, WG, and RC), l represents 3 statistics $\left(\rho, \sigma_{\varepsilon}\right.$, and AMB is obtained as the average of above defined two experiments), $M$ represents the method of interest, and $\mathrm{U}$ is the added utility with respect to REG1. To ensure that $\mathrm{U}$ is always positive for the improvements and negative for the degraded results, the bias and standard deviation statistics are multiplied by -1 . $U$ is calculated only for the following selected methods: i) REGL2, ii) better performing MARS and MARSL, iii) CDF, iv) better performing GEN and GENL, v) better performing of SVM and SVML, vi) best performing type of copula (including all of the lagged types), vii) best performing type of ANN (including all of the lagged types), viii) the method (among the 31 methods) that gives the best statistical training ("Tr_best"), and ix) the method that gives the best statistics when the validation data are used ("Best"). For example, if MARSL gives the best $\rho$ over LR using training data, then MARSL is selected as the "Tr_best" method for $\rho$ over LR, whereas another method may perform better using the validation data ("Best"). Comparisons of U are performed separately over four watersheds. Similarly, these comparisons are repeated for each performance statistic $\left(\rho, \sigma_{\varepsilon}\right.$, and AMB, 3 total). 


\section{Results and Discussion}

The statistics of the LPRM and watershed average soil moisture datasets are analyzed (Table 4) prior to evaluating the results of the rescaling experiment. On average, there are 1600 days where the LPRM and watershed average data are mutually available between June 2002 and July 2009. Two different experiments are conducted using two different training datasets, and validation dataset are used to check the consistency of the results. On average, 1200 of the available data points are used for training, for both experiments, whereas the remaining $(\sim 400)$ unused data points are left for independent validation. Overall, the statistics $(\mu, \sigma$, and lag1 autocorrelation) of the datasets (Table 4) are very similar for the training and validation periods for both experiments (statistical significance tests are not performed). Unscaled original LPRM time series have 2-4 times larger $\mu$ and $\sigma$ than the watershed average time series, which can also be seen in the scatterplots of the datasets (Figure 2, upper row). This clearly shows that these datasets should be reconciled in some statistical sense (e.g., Figure 2, middle row) before they can be meaningfully compared or used to create a homogenous and consistent time series. The watershed average time series has $3.4 \%, 4.5 \%, 0.1 \%$, and $5.5 \%$ missing data (results not shown) for the LR, LW, WG, and RC watersheds, respectively. The time series obtained over LR and RC have more missing data than those obtained over LW and WG, yet the autocorrelation values over RC are statistically significantly higher than the values over LW, WG, and WG (for both the LPRM and watershed average datasets). Higher autocorrelation values, despite more missing data, imply calculation differences between $\mathrm{RC}$, and the remaining 3 watershed average data could be real; they may not be considerably impacted by the missing data, even though the LPRM autocorrelations are, on average, 0.10 lower than the watershed average values (perhaps due to the higher noise component). 
The statistics $\rho, \mathrm{AMB}$, and $\sigma_{\varepsilon}$ (equations 16-18) for the 31 experiments for the training and 549 validation periods are presented in Tables 5-6 and Figures 3-5. Table 5 shows the training and 550 validation results numerically. Figures 3 and 4 show the average values obtained for four 551 watersheds using the data presented in Table 5. Table 6 shows the added utility of the methods 552 (only the best performing types are presented). Figure 5 represents the average values obtained for 553 the four watersheds presented in Table 6. Here, the U values are calculated with respect to the 554 REG1 values (Table 5) using equation 17. In general, a higher $\rho$ is almost always associated with 555 a lower $\sigma_{\varepsilon}$ for both validation and training datasets (Tables 5-6), implying that these statistics are 556 consistent when representing the accuracy of the analyzed dataset. Overall, the relative 557 performances of these 31 methods are very consistent for the training and validation datasets (i.e., 558 better performing methods using training datasets also performed better when using validation 559 datasets). This consistency can also be seen in the $U$ values (Table 6 and Figure 5). This provides 560 inferences about the relative performances of these rescaling methods when using training datasets, 561 which could provide very meaningful information about independent data scenarios. The 562 consistency between the training and validation results also supports the selection of training and 563 validation periods; these two periods may not have a considerable difference in terms of the 564 relation between the LPRM and watershed average data, as well as in terms of the relative 565 performances of the rescaling methods.

On average, the GENL and ELMANL ANN methods yield a $\rho$ improvement of $\sim 0.05$ using 567 independent validation datasets. This improvement is lower $(0.02-0.04 \rho$ improvement $)$ for the 568 SVML, MARSL, REGL2, and NORMALL methods (Figure 5 and Table 6). In contrast to its wide 569 use, the CDF method has no added skill (Figure 5); in fact, on average, it yields degraded 570 correlations compared to REG1 when validated using independent data (Table 6). When the 
571 method selection is consistent with the training results, these Tr_best methods yield better U values

572 than any method alone, with $U$ values that are similar to the best validation results ("Best")

573 approximately $75 \%$ of the time (Figure 5). These results further support the above discussion that

574 it is better to make a rescaling method selection that is consistent with the training data statistics,

575 when this selection can yield better validation results than the selection of any other method alone.

576 When the results are averaged over all of the watersheds, all of the nonlinear methods

577 (except for JOE) demonstrated improved correlations compared to the REG1 correlations using

578 the training datasets (Figure 3). When validation datasets are used, MARS, GEN, SVM, all four

579 ANNs, and NORMAL still have superior correlations compared to REG1 (Table 5 and Figure 4).

580 In particular, the improvements over LR, LW, and RC using GENL, SVML, and ELMANL (0.083,

5810.090 , and 0.135), respectively, are much higher than the improvements over other locations via

582 various methods (Table 6). Compared to the best performing linear method using the validation

583 data (MARSL), on average, the GENL, SVML, ELMAN, ELMANL, JORDAN, and JORDANL

584 nonlinear methods yielded better results (Figure 4). These outcomes stressed the results of the first-

585 order linear regression, which can be improved via higher order or more complex linear methods,

586 and there is still added utility that can be gained via nonlinear methods compared to linear methods.

587 Thus, nonlinear methods have a higher potential to give more accurate results compared to linear

588 methods, and as a result, the existing nonlinear relations cannot be captured through linear 589 methods.

590 Soil moisture products have high autocorrelation; hence, two of the most recent soil 591 moisture observations have a high linear dependence (Table 4 and Figure 2 bottom row). The use 592 of lagged observations, in addition to the unscaled observations in a first-order linear framework 593 (REGL), improves the statistics compared to REG1. However, the GEN and SVM methods yield, 
on average, better improvements than linear methods, such as REG1 and MARS (Table 7), particularly over LR and LW (the $\rho$ difference between GENL and GEN over LR is 0.086 and the SVML and SVM difference over LW is 0.083). These results show that the overall nonlinear methods better utilize the lagged observation information (Table 4) and have a higher potential to improve the results compared to the linear methods, even though the degree of improvement varies

599 for different methods. The ANN methods do not have much added skill via lagged observations, 600 perhaps because these methods already utilize the lagged observation information. These results 601 further highlight the higher potential of nonlinear methods in rescaling soil moisture datasets.

When the parameters obtained using the training datasets are implemented over the validation datasets, some skill loss (i.e., artificial skill) is often observed because all of the methods 604 overfit their datasets to some extent. Loosely speaking, an increase of 0.06 or 0.10 in $\rho$ constitutes 605 a statistically significant increase, especially when 1200 or 400 samples are used for training or 606 validation experiments, respectively (e.g., an increase from 0.60 to 0.66 or from 0.60 to 0.70 ). 607 Accordingly, MARS, SVM, and ELMAN yield significant $\rho$ improvements (with respect to REG1 $608 \rho$ ) over half of the training cases, whereas GEN, FRANK, and JORDAN also yield significant 609 improvements over some locations (Table 5; most of the training improvements are over LW and 610 RC, and only a few are over WG). By contrast, for validation experiments, only ELMAN and 611 JORDAN resulted in significant $\rho$ improvements (both over RC), showing that most of these 612 improvements are artificial skills. Here, the degree to which the methods overfit the datasets is 613 evaluated through the comparisons of $\rho$ for the validation datasets (Figure 4) versus the training 614 datasets (Figure 3), where higher differences indicate a higher degree of artificial skill. These 615 differences show the artificial skill in $\rho$ to be approximately 50\% for ANN (ELMANL only have $61618 \%$ artificial skill); $\sim 65-80 \%$ for GEN, MARS, and SVM; and 100\% for REGL2, CDF and the 
617 copula methods, on average (NORMALL has an artificial skill of only 65\%). These results stress

618 the use of independent validation data to avoid artificial skill.

The skills of nonlinear methods are heavily impacted by the number of iterations performed

620 to optimally obtain certain parameters. By contrast, increasing the degree of these iterations

621 eventually results in overtraining and hence overfitting. For example, in this study, the maximum

622 number of iterations for ANN simulations is set at 1000. When this number is increased to 100,000,

623 training correlations can be obtained between the reference and rescaled products (as high as 0.90

624 for certain cases). However, this gained training skill is quickly lost when the obtained ANN

625 configurations and parameters are utilized on independent validation data. Such dramatic

626 differences are more common for ANN than other methods (GEN, SVM, and copula), whereas the

627 degree of overfitting using other methods does not depend as much on user specifications as ANN

628 (results not shown).

629 Among the copula methods, CLAYTON, GUMBEL, and JOE have asymmetric tail 630 dependence properties (strong in one tail and weak in the other) and do not perform as well as 631 NORMAL or FRANK, which have symmetric tail dependence for both training and validation 632 experiments (Table 5). Both the copula and $\mathrm{CDF}$ methods use $\mathrm{CDF}_{\mathrm{X}}$ and $\mathrm{CDF}_{\mathrm{Y}}$ to rescale 633 observations. However, it is stressed that the performances of copula methods are very sensitive 634 to the $C_{X \mid Y}$ values (equation 16), which are selected during training. The optimality of these $C_{X \mid Y}$ 635 values depends on the objective of the training process (e.g., the minimization of AMB only, the 636 maximization of $\rho$ only, the minimization AMB and $\sigma_{\epsilon}$ simultaneously, or the minimization of

$637 \mathrm{AMB}$ and $\sigma_{\epsilon}$, and the maximization of $\rho$ simultaneously). In this study, the penalty function is 638 formed and $\mathrm{C}_{\mathrm{X} \mid \mathrm{Y}}$ values are obtained in a way that training is penalized for increased AMB and $\sigma_{\epsilon}$ 639 and decreased $\rho$. Investigations for the added utility of lagged observations show only Normal 
640 Copula (Elliptical family) utilizing this information, whereas the remaining copula types

641 (Archimedean family) result in degraded rescaled products, especially when lagged observations

642 are also used and validated using independent data (Table 5 and Figure 4). This result is consistent

643 with the study of Afshar et al. (2016), who found the Elliptical family to be better at capturing the

644 dependency among variables than the copula functions of the Archimedean family.

645

646

\section{Conclusions}

In this study, LPRM soil moisture datasets are rescaled to station-based datasets over four

648 USDA ARS watersheds to reduce the systematic differences between datasets. The rescaled

649 datasets are validated by using independent data that are not used in the training part. This study

650 is the first to perform a comprehensive comparison of the performances of various linear (VAR,

651 TCA, REG1, REG2, REGL, REGL2, and MARS) and nonlinear (CDF, GEN, SVM, ANN, and

652 copula) methods (total 31 methods); the first to use the REG2, REGL, REGL2, MARS, GEN,

653 SVM, and ANN methods to explicitly rescale the soil moisture datasets in the framework of soil

654 moisture rescaling; and the first to comprehensively investigate the added utility of lagged

655 observations in the soil moisture rescaling framework.

656 The relative performances of methods using training and validation datasets are consistent;

657 the rescaling method that results in a more accurate rescaled product using training data also results

658 in a more accurate rescaled product using validation data, and the best performing method using

659 the training datasets yields better results than any other individual method that uses the validation

660 datasets. Although the actual performances of the rescaling methods might change for different

661 datasets, it is viable that a similar consistency would also exist for other datasets that are not used

662 in this study. Such a consistency between the training and validation results gives confidence to 
663 the user in their selection of the rescaling method, particularly in the operational implementation 664 of rescaling methods.

A large majority of the related variability between products are due to first-order linear 666 relations. Although multiple linear regression-based rescaling methods slightly improve the 667 rescaled product statistics, the training and the validation statistics consistently show that nonlinear 668 methods resulted in a more accurate rescaled product than linear methods. Overall, GENL and 669 ELMAN improved independent validation dataset correlations the best (on average 0.05), whereas 670 improvements reached as high as 0.14 at individual locations (ELMAN over RC). Among nonlinear methods, ELMAN exhibits superior performance, particularly when the

672 datasets are highly autocorrelated (over RC), whereas the GEN and SVM methods exhibit superior 673 performance when the lagged observations are also used as predictors (over LR and LW). 674 Although lagged observations improve the rescaled product statistics when datasets are rescaled 675 linearly, nonlinear methods yield better statistics than linear methods. This highlights that lagged 676 observations, which contain valuable information in the soil moisture rescaling framework as in 677 the TCA framework (Crow et al., 2015; Su et al., 2014; Zwieback et al., 2013). Nonlinear methods 678 have higher added utility potential than linear methods in using lagged observations, in addition to 679 their overall higher rescaling potential compared to the linear methods.

680 The higher rescaling potential and lagged observation utilization potential compared to 681 linear methods clearly show that the soil moisture datasets used in this study have nonlinear 682 relations that cannot be modeled using linear methods. It is also viable that such nonlinear 683 relationships may exist between other soil moisture datasets that are not used in this study. These 684 results imply that the soil moisture inter-comparison studies (Albergel et al., 2012; Brocca et al., 685 2011; Hain et al., 2011; Mladenova et al., 2014; Parinussa et al., 2014; Wagner et al., 2014) and 
non-data assimilation type blending studies (Leroux et al., 2014; Liu, et al., 2012, 2014) may benefit from these nonlinear rescaling methods, given the key results in this study. The performance metrics $\left(\rho, \sigma_{\varepsilon}\right.$, and AMB) can be considerably (in some cases statistically significantly) improved via such nonlinear methods, whereas their degree of improvements may be dataset specific.

Recent studies highlight the utility of simple API models compared to more complex models (Crow et al., 2012; Han et al., 2014; Yilmaz et al., 2016), particularly in studies aiming to methodologically improve current techniques (Crow \& Yilmaz, 2014; Yilmaz \& Crow, 2013). Given that such simple models have better skills in drought studies (Crow et al., 2012), such models can be used to create long and homogenous time series, expanding to historical dates, where precipitation observations are available. To ensure the consistency of the units of the model values with traditional ground observations, this model time series could be rescaled to available ground observations, relying on the consistency found between the training and the validation datasets, where mutually available datasets can be used to retrieve the necessary parameters.

Overall, it is likely that more accurate nonlinearly rescaled products will improve applications that are better related to studies using linearly rescaled products. For example, assimilation experiments require observations to be rescaled into model space before they can be merged. By definition, an assimilation of more accurate observations (e.g., obtained via nonlinearly rescaling methods) in models always results in a more accurate analysis than the assimilation of less accurate observations (unless the underlying assumptions are not met). On the one hand, Yilmaz and Crow (2013) show an assimilation analysis accuracy that depends on the degree to which the signal component of observations should be rescaled to the signal component of the model, rather than the overall product differences that are alleviated directly, as done in this 
study. Similarly, Su et al. (2014) and Zwieback et al. (2016) show that matching this signal component is also very important for error characterization. Consistently, Yilmaz and Crow (2013) demonstrate TCA matching of the signal components of the datasets and a better rescaling method than REG1 in the assimilation framework. The current study does not involve assimilation experiments and does not compare the actual signal components of the datasets; hence, only the explicit use of nonlinear methods in the assimilation framework (future study) may convey the real added utility via such nonlinear methods in assimilation experiments. On the other hand, an analysis accuracy improvement through the use of more accurate observations is inherent to the definition of assimilation studies. It is our expectation that the marginal gains in the rescaled dataset accuracy (e.g., $\sim 0.02 \rho$ improvements) might not translate into large gains in assimilation analysis errors, whereas statistically significant improvements (e.g., $0.10-0.14)$ might translate into meaningful assimilation analysis improvements. Again, this expectation needs to be validated using a dedicated assimilation experiment.

\section{Acknowledgments}

The authors would like to thank three anonymous reviewers for their constructive comments. The authors would also like to thank the International Soil Moisture Network for the USDA ARS station-based soil moisture datasets, Vrije Universiteit Amsterdam (Robert Parinussa, personal communication) for the LPRM datasets, and NASA for the GLDAS datasets (downloaded from http://mirador.gsfc.nasa.gov). This research was supported by the EU Marie Curie Seventh Framework Programme FP7-PEOPLE-2013-CIG project number 630110 and The Scientific and Technological Research Council of Turkey (TUBITAK) Grant 3501 project number 114 Y676. 


\section{References}

Afshar, M.H., Sorman, A.U., Yilmaz, M.T., 2016. Conditional Copula-Based Spatial-Temporal Drought Characteristics Analysis - Case Study over Turkey, Water-141409

Albergel, C., de Rosnay, P., Gruhier, C., Muñoz-Sabater, J., Hasenauer, S., Isaksen, L., Kerr, Y., Wagner, W., 2012. Evaluation of remotely sensed and modelled soil moisture products using global ground-based in situ observations. Remote Sens. Environ. 118, 215-226. doi:10.1016/j.rse.2011.11.017

Anderson, W.B., Zaitchik, B.F., Hain, C.R., Anderson, M.C., Yilmaz, M.T., Mecikalski, J., Schultz, L., 2012. Towards an integrated soil moisture drought monitor for East Africa. Hydrol. Earth Syst. Sci. 16, 2893-2913. doi:10.5194/hess-16-2893-2012

Andrés Suárez, J., Lorca Fernández, P., Cos Juez, F.J. de, Sánchez Lasheras, F., 2011. Bankruptcy forecasting: A hybrid approach using Fuzzy c-means clustering and Multivariate Adaptive Regression Splines (MARS). Scopus.

Bergmeir, C.N., Benítez Sánchez, J.M., 2012. Neural Networks in R Using the Stuttgart Neural Network Simulator: RSNNS.

Brocca, L., Hasenauer, S., Lacava, T., Melone, F., Moramarco, T., Wagner, W., Dorigo, W., Matgen, P., Martínez-Fernández, J., Llorens, P., Latron, J., Martin, C., Bittelli, M., 2011. Soil moisture estimation through ASCAT and AMSR-E sensors: An intercomparison and validation study across Europe. Remote Sens. Environ. 115, 3390-3408. doi:10.1016/j.rse.2011.08.003

Brocca, L., Melone, F., Moramarco, T., Wagner, W., Albergel, C., 2013. Scaling and Filtering Approaches for the Use of Satellite Soil Moisture Observations, in: Remote Sensing of Energy Fluxes and Soil Moisture Content. CRC Press, pp. 411-426. doi:10.1201/b15610-21 
CHEN, S., BILLINGS, S.A., 1992. Neural networks for nonlinear dynamic system modelling and identification. Int. J. Control 56, 319-346. doi:10.1080/00207179208934317

CLAYTON, D.G., 1978. A model for association in bivariate life tables and its application in epidemiological studies of familial tendency in chronic disease incidence. Biometrika 65, 141-151. doi:10.1093/biomet/65.1.141

Cortes, C., Vapnik, V., 1995. Support-Vector Networks. Mach. Learn. 20, 273-297. doi:10.1023/A:1022627411411

Cosh, M.H., Jackson, T.J., Moran, S., Bindlish, R., 2008. Temporal persistence and stability of surface soil moisture in a semi-arid watershed. Remote Sens. Environ. 112, 304-313. doi:10.1016/j.rse.2007.07.001

Cosh, M.H., Jackson, T.J., Starks, P., Heathman, G., 2006. Temporal stability of surface soil moisture in the Little Washita River watershed and its applications in satellite soil moisture product validation. J. Hydrol. 323, 168-177. doi:10.1016/j.jhydrol.2005.08.020

Crow, W.T., Crow, W.T., 2007. A Novel Method for Quantifying Value in Spaceborne Soil Moisture Retrievals. J. Hydrometeorol. 8, 56-67. doi:10.1175/JHM553.1

Crow, W.T., Koster, R.D., Reichle, R.H., Sharif, H.O., 2005. Relevance of time-varying and timeinvariant retrieval error sources on the utility of spaceborne soil moisture products. Geophys. Res. Lett. 32, L24405. doi:10.1029/2005GL024889

Crow, W.T., Kumar, S. V., Bolten, J.D., 2012. On the utility of land surface models for agricultural drought monitoring. Hydrol. Earth Syst. Sci. 16, 3451-3460. doi:10.5194/hess-16-3451-2012 Crow, W.T., Su, C.-H., Ryu, D., Yilmaz, M.T., 2015. Optimal averaging of soil moisture predictions from ensemble land surface model simulations. Water Resour. Res. 51, 92739289. doi:10.1002/2015WR016944 
Crow, W.T., Yilmaz, M.T., 2014. The Auto-Tuned Land Data Assimilation System (ATLAS). Water Resour. Res. 50, 371-385. doi:10.1002/2013WR014550

Crow, W.T., Zhan, X., 2007. Continental-Scale Evaluation of Remotely Sensed Soil Moisture Products. IEEE Geosci. Remote Sens. Lett. 4, 451-455. doi:10.1109/LGRS.2007.896533

De Andrés, J., Lorca, P., de Cos Juez, F.J., Sánchez-Lasheras, F., 2011. Bankruptcy forecasting: A hybrid approach using Fuzzy c-means clustering and Multivariate Adaptive Regression Splines (MARS). Expert Syst. Appl. 38, 1866-1875. doi:10.1016/j.eswa.2010.07.117

Dirmeyer, P.A., Guo, Z., Gao, X., Dirmeyer, P.A., Guo, Z., Gao, X., 2004. Comparison, Validation, and Transferability of Eight Multiyear Global Soil Wetness Products. J. Hydrometeorol. 5, 1011-1033. doi:10.1175/JHM-388.1

Dorigo, W.A., Wagner, W., Hohensinn, R., Hahn, S., Paulik, C., Xaver, A., Gruber, A., Drusch, M., Mecklenburg, S., van Oevelen, P., Robock, A., Jackson, T., 2011. The International Soil Moisture Network: a data hosting facility for global in situ soil moisture measurements. Hydrol. Earth Syst. Sci. 15, 1675-1698. doi:10.5194/hess-15-1675-2011

Dorigo, W., de Jeu, R., Chung, D., Parinussa, R., Liu, Y., Wagner, W., Fernández-Prieto, D., 2012. Evaluating global trends (1988-2010) in harmonized multi-satellite surface soil moisture. Geophys. Res. Lett. 39, n/a-n/a. doi:10.1029/2012GL052988

Draper, C.S., Walker, J.P., Steinle, P.J., de Jeu, R.A.M., Holmes, T.R.H., 2009. An evaluation of AMSR-E derived soil moisture over Australia. Remote Sens. Environ. 113, 703-710. doi:10.1016/j.rse.2008.11.011

Drusch, M., 2007. Initializing numerical weather prediction models with satellite-derived surface soil moisture: Data assimilation experiments with ECMWF's Integrated Forecast System and the TMI soil moisture data set. J. Geophys. Res. 112, D03102. doi:10.1029/2006JD007478 
801

802

803

804

805

806

807

808

809

810

811

812

813

814

815

816

817

818

819

820

821

822

823

Drusch, M., Wood, E.F., Gao, H., 2005. Observation operators for the direct assimilation of TRMM microwave imager retrieved soil moisture. Geophys. Res. Lett. 32, L15403. doi:10.1029/2005GL023623

Ek, M.B., Mitchell, K.E., Lin, Y., Rogers, E., Grunmann, P., Koren, V., Gayno, G., Tarpley, J.D., 2003. Implementation of Noah land surface model advances in the National Centers for Environmental Prediction operational mesoscale Eta model. J. Geophys. Res. 108, 8851. doi:10.1029/2002JD003296

Elman, J.L., 1990. Finding structure in time. Cogn. Sci. 14, 179-211. doi:10.1016/03640213(90)90002-E

Flasch, O., Mersmann, O., Bartz-Beielstein, T., Stork, J., Zaefferer, M., 2015. R genetic programming framework. $\mathrm{R}$ package version $0.4-1$.

Frahm, G., Junker, M., Szimayer, A., 2003. Elliptical copulas: applicability and limitations, Statistics \& Probability Letters. doi:10.1016/S0167-7152(03)00092-0

Friedman, J.H., 1991. Multivariate Adaptive Regression Splines. Ann. Stat. 19, 1-67. doi:10.1214/aos/1176347963

Genest, C., 1987. Frank's family of bivariate distributions. Biometrika 74, 549-555. doi:10.1093/biomet/74.3.549

Genest, C., Favre, A.-C., 2007. Everything You Always Wanted to Know about Copula Modeling but Were Afraid to Ask. J. Hydrol. Eng. 12, 347-368. doi:10.1061/(ASCE)10840699(2007)12:4(347)

Gill, M.K., Asefa, T., Kemblowski, M.W., McKee, M., 2006. SOIL MOISTURE PREDICTION USING SUPPORT VECTOR MACHINES. J. Am. Water Resour. Assoc. 42, 1033-1046. doi:10.1111/j.1752-1688.2006.tb04512.x 
824 Gruber, A., Su, C.-H., Zwieback, S., Crow, W., Dorigo, W., Wagner, W., 2016. Recent advances

825

826

827

828

829

830

831

832

833

834

835

836

837

842

843

844

845

in (soil moisture) triple collocation analysis. Int. J. Appl. Earth Obs. Geoinf. 45, 200-211. doi:10.1016/j.jag.2015.09.002

Guang-Bin Huang, Babri, H.A., 1998. Upper bounds on the number of hidden neurons in feedforward networks with arbitrary bounded nonlinear activation functions. IEEE Trans. Neural Networks 9, 224-229. doi:10.1109/72.655045

Gumbel, E.J., 1960. Distributions des valeurs extr^emes en plusieurs dimensions, Publications de l'Institut de Statistique de l'Universit'e de Paris. Distributions des valeurs extr^emes en plusieurs dimensions, Paris, France.

Hain, C.R., Crow, W.T., Mecikalski, J.R., Anderson, M.C., Holmes, T., 2011. An intercomparison of available soil moisture estimates from thermal infrared and passive microwave remote sensing and land surface modeling. J. Geophys. Res. Atmos. 116, 1-18. doi:10.1029/2011JD015633

Han, E., Crow, W.T., Holmes, T., Bolten, J., 2014. Benchmarking a Soil Moisture Data Assimilation System for Agricultural Drought Monitoring. J. Hydrometeorol. 15, 1117-1134. doi:10.1175/JHM-D-13-0125.1

Hastie, T., Tibshirani, R., Friedman, J., 2009. The Elements of Statistical Learning, Springer Series in Statistics. Springer New York, New York, NY. doi:10.1007/978-0-387-84858-7

Hernández, N., Kiralj, R., Ferreira, M.M.C., Talavera, I., 2009. Critical comparative analysis, validation and interpretation of SVM and PLS regression models in a QSAR study on HIV-1 protease inhibitors. Chemom. Intell. Lab. Syst. 98, 65-77. doi:10.1016/j.chemolab.2009.04.012 
Hofert, M., Kojadinovic, I., Maechler, M., Yan, J., 2012. Copula: Multivariate Dependence with Copulas. R package version 0.999-13.

Jackson, T.J., Cosh, M.H., Bindlish, R., Starks, P.J., Bosch, D.D., Seyfried, M., Goodrich, D.C., Moran, M.S., Du, J., 2010. Validation of Advanced Microwave Scanning Radiometer Soil Moisture Products. IEEE Trans. Geosci. Remote Sens. 48, 4256-4272. doi:10.1109/TGRS.2010.2051035

Jackson, T.J., Bindlish, R., Cosh, M.H., Zhao, T., Starks, P.J., Bosch, D.D., Seyfried, M., Moran, M.S., Goodrich, D.C., Kerr, Y.H., Leroux, D., 2012. Validation of Soil Moisture and Ocean Salinity (SMOS) Soil Moisture Over Watershed Networks in the U.S. IEEE Trans. Geosci. Remote Sens. 50, 1530-1543. doi:10.1109/TGRS.2011.2168533

Joe, H., 1997. Multivariate models and multivariate dependence concepts. CRC Press, US.

Jordan, M.I., 1997. Serial Order: A Parallel Distributed Processing Approach. NorthHolland/Elsevier Science Publishers, pp. 471-495. doi:10.1016/S0166-4115(97)80111-2

Kentel, E., 2009. Estimation of river flow by artificial neural networks and identification of input vectors susceptible to producing unreliable flow estimates. J. Hydrol. 375, 481-488. doi:10.1016/j.jhydrol.2009.06.051

Koster, R.D., Dirmeyer, P.A., Guo, Z., Bonan, G., Chan, E., Cox, P., Gordon, C.T., Kanae, S., Kowalczyk, E., Lawrence, D., Liu, P., Lu, C.-H., Malyshev, S., McAvaney, B., Mitchell, K., Mocko, D., Oki, T., Oleson, K., Pitman, A., Sud, Y.C., Taylor, C.M., Verseghy, D., Vasic, R., Xue, Y., Yamada, T., 2004. Regions of Strong Coupling Between Soil Moisture and Precipitation. Science (80-. ). 305, 1138-1140. doi:10.1126/science.1100217 
Koster, R.D., Guo, Z., Yang, R., Dirmeyer, P.A., Mitchell, K., Puma, M.J., Koster, R.D., Guo, Z., Yang, R., Dirmeyer, P.A., Mitchell, K., Puma, M.J., 2009. On the Nature of Soil Moisture in Land Surface Models. J. Clim. 22, 4322-4335. doi:10.1175/2009JCLI2832.1

Koza, J., 1994. Genetic programming as a means for programming computers by natural selection. Stat. Comput. 4, 87-112. doi:10.1007/BF00175355

Lawrence, J.E., Hornberger, G.M., 2007. Soil moisture variability across climate zones. Geophys. Res. Lett. 34, 1-5. doi:10.1029/2007GL031382

Leroux, D.J., Kerr, Y.H., Wood, E.F., Sahoo, A.K., Bindlish, R., Jackson, T.J., 2014. An Approach to Constructing a Homogeneous Time Series of Soil Moisture Using SMOS. IEEE Trans. Geosci. Remote Sens. 52, 393-405. doi:10.1109/TGRS.2013.2240691

Liu, D., Yu, Z., L, H., 2010. Data assimilation using support vector machines and ensemble Kalman filter for multi-layer soil moisture prediction. Water Sci. Eng. 3, 361-377. doi:10.3882/j.issn.1674-2370.2010.04.001

Liu, Y.Y., Dorigo, W.A., Parinussa, R.M., de Jeu, R.A.M., Wagner, W., McCabe, M.F., Evans, J.P., van Dijk, A.I.J.M., 2012. Trend-preserving blending of passive and active microwave soil moisture retrievals. Remote Sens. Environ. 123, 280-297. doi:10.1016/j.rse.2012.03.014

Liu, Y.Y., Parinussa, R.M., Dorigo, W.A., De Jeu, R.A.M., Wagner, W., van Dijk, A.I.J.M., McCabe, M.F., Evans, J.P., 2011. Developing an improved soil moisture dataset by blending passive and active microwave satellite-based retrievals. Hydrol. Earth Syst. Sci. 15, 425-436. doi:10.5194/hess-15-425-2011

Meyer, D., Dimitriadou, E., Hornik, K., Weingessel, A., Leisch, F., Chang, C., Lin, C., 2015. Misc Functions of the Department of Statistics, Probability Theory Group (Formerly: E1071), R package version 1.6-7. 
Milborrow, S., n.d. earth: Multivariate Adaptive Regression Splines, R package version 4.4.5.

Miralles, D.G., De Jeu, R.A.M., Gash, J.H., Holmes, T.R.H., Dolman, A.J., 2011. Magnitude and variability of land evaporation and its components at the global scale. Hydrol. Earth Syst. Sci. 15, 967-981. doi:10.5194/hess-15-967-2011

Mladenova, I.E., Jackson, T.J., Njoku, E., Bindlish, R., Chan, S., Cosh, M.H., Holmes, T.R.H., de Jeu, R.A.M., Jones, L., Kimball, J., Paloscia, S., Santi, E., 2014. Remote monitoring of soil moisture using passive microwave-based techniques - Theoretical basis and overview of selected algorithms for AMSR-E. Remote Sens. Environ. 144, 197-213. doi:10.1016/j.rse.2014.01.013

Murata, N., Yoshizawa, S., Amari, S., 1994. Network information criterion-determining the number of hidden units for an artificial neural network model. IEEE Trans. Neural Networks 5, 865-872. doi:10.1109/72.329683

Nelsen, R.B., 1999. An Introduction to Copulas, Lecture Notes in Statistics. Springer New York, New York, NY. doi:10.1007/978-1-4757-3076-0

Notarnicola, C., Angiulli, M., Posa, F., 2008. Soil moisture retrieval from remotely sensed data: Neural network approach versus Bayesian method. IEEE Trans. Geosci. Remote Sens. 46, 547-557. doi:10.1109/TGRS.2007.909951

Olson, D.L., Delen, D., 2008. Advanced data mining techniques. Springer.

Owe, M., de Jeu, R., Holmes, T., 2008. Multisensor historical climatology of satellite-derived global land surface moisture. J. Geophys. Res. 113, F01002. doi:10.1029/2007JF000769

Owe, M., de Jeu, R., Walker, J., 2001. A methodology for surface soil moisture and vegetation optical depth retrieval using the microwave polarization difference index. IEEE Trans. Geosci. Remote Sens. 39, 1643-1654. doi:10.1109/36.942542 
913 Paloscia, S., Pampaloni, P., Pettinato, S., Santi, E., 2008. A Comparison of Algorithms for 914 Retrieving Soil Moisture from ENVISAT/ASAR Images. IEEE Trans. Geosci. Remote Sens. 46, 3274-3284. doi:10.1109/TGRS.2008.920370

916 Parinussa, R.M., Holmes, T.R.H., Wanders, N., Dorigo, W.A., de Jeu, R.A.M., Parinussa, R.M., 917 Holmes, T.R.H., Wanders, N., Dorigo, W.A., Jeu, R.A.M. de, 2015. A Preliminary Study toward Consistent Soil Moisture from AMSR2. J. Hydrometeorol. 16, 932-947. doi:10.1175/JHM-D-13-0200.1

920

921

922

923

924

925

926

927

928

929

930

931

932

933

934

935

Parinussa, R.M., Holmes, T.R.H., Yilmaz, M.T., Crow, W.T., 2011. The impact of land surface temperature on soil moisture anomaly detection from passive microwave observations. Hydrol. Earth Syst. Sci. 15, 3135-3151. doi:10.5194/hess-15-3135-2011

Parinussa, R.M., Wang, G., Holmes, T.R.H., Liu, Y.Y., Dolman, A.J., de Jeu, R.A.M., Jiang, T., Zhang, P., Shi, J., 2014. Global surface soil moisture from the Microwave Radiation Imager onboard the Fengyun-3B satellite. Int. J. Remote Sens. 35, 7007-7029. doi:10.1080/01431161.2014.960622

Parinussa, R.M., Yilmaz, M.T., Anderson, M.C., Hain, C.R., de Jeu, R.A.M., 2014. An intercomparison of remotely sensed soil moisture products at various spatial scales over the Iberian Peninsula. Hydrol. Process. 28, 4865-4876. doi:10.1002/hyp.9975

Poggio, T., Girosi, F., 1990. Networks for approximation and learning. Proc. IEEE 78, 1481-1497. doi:10.1109/5.58326

Prigent, C., Aires, F., Rossow, W.B., Robock, A., 2005. Sensitivity of satellite microwave and infrared observations to soil moisture at a global scale: Relationship of satellite observations to in situ soil moisture measurements. J. Geophys. Res. 110, D07110. doi:10.1029/2004JD005087 
R Core Team, 2015. R: A language and environment for statistical computing. R Foundation for Statistical Computing. Vienna. Austria.

Reichle, R.H., Crow, W.T., Koster, R.D., Sharif, H.O., Mahanama, S.P.P., 2008. Contribution of soil moisture retrievals to land data assimilation products. Geophys. Res. Lett. 35, L01404. doi:10.1029/2007GL031986

Reichle, R.H., Koster, R.D., 2005. Global assimilation of satellite surface soil moisture retrievals into the NASA Catchment land surface model. Geophys. Res. Lett. 32, L02404. doi:10.1029/2004GL021700

Reichle, R.H., Koster, R.D., 2004. Bias reduction in short records of satellite soil moisture. Geophys. Res. Lett. 31, L19501. doi:10.1029/2004GL020938

Rochester, N., Holland, J., Haibt, L., Duda, W., 1956. Tests on a cell assembly theory of the action of the brain, using a large digital computer. IEEE Trans. Inf. Theory 2, 80-93. doi:10.1109/TIT.1956.1056810

Rodell, M., Houser, P.R., Jambor, U., Gottschalck, J., Mitchell, K., Meng, C.-J., Arsenault, K., Cosgrove, B., Radakovich, J., Bosilovich, M., Entin*, J.K., Walker, J.P., Lohmann, D., Toll, D., Rodell, M., Houser, P.R., Jambor, U., Gottschalck, J., Mitchell, K., Meng, C.-J., Arsenault, K., Cosgrove, B., Radakovich, J., Bosilovich, M., Entin*, J.K., Walker, J.P., Lohmann, D., Toll, D., 2004. The Global Land Data Assimilation System. Bull. Am. Meteorol. Soc. 85, 381-394. doi:10.1175/BAMS-85-3-381

Rodriguez-Fernandez, N.J., Aires, F., Richaume, P., Kerr, Y.H., Prigent, C., Kolassa, J., Cabot, F., Jimenez, C., Mahmoodi, A., Drusch, M., 2015. Soil Moisture Retrieval Using Neural Networks: Application to SMOS. IEEE Trans. Geosci. Remote Sens. 53, 5991-6007. doi:10.1109/TGRS.2015.2430845 
Rosenblatt, F., 1958. The perceptron: A probabilistic model for information storage and organization in the brain. Psychol. Rev. 65, 386-408. doi:10.1037/h0042519

Scipal, K., Holmes, T., de Jeu, R., Naeimi, V., Wagner, W., 2008. A possible solution for the problem of estimating the error structure of global soil moisture data sets. Geophys. Res. Lett. 35, L24403. doi:10.1029/2008GL035599

Sharda, V.N., Prasher, S.O., Patel, R.M., Ojasvi, P.R., Prakash, C., 2008. Performance of Multivariate Adaptive Regression Splines (MARS) in predicting runoff in mid-Himalayan micro-watersheds with limited data. Hydrol. Sci. Journal-Journal Des Sci. Hydrol. 53, 11651175. doi:10.1623/hysj.53.6.1165

Sheela, K.G., Deepa, S.N., Sheela, K.G., Deepa, S.N., 2013. Review on Methods to Fix Number of Hidden Neurons in Neural Networks. Math. Probl. Eng. 2013, 1-11. doi:10.1155/2013/425740

Sklar, A., 1959. Fonctions de Répartition à n Dimensions et Leurs Marges. Publications de l'Institut de Statistique de L'Université de Paris.

Smola, A.J., Schölkopf, B., 2004. A tutorial on support vector regression. Stat. Comput. 14, 199222. doi:10.1023/B:STCO.0000035301.49549.88

Stoffelen, A., 1998. Toward the true near-surface wind speed: Error modeling and calibration using triple collocation. J. Geophys. Res. Ocean. 103, 7755-7766. doi:10.1029/97JC03180

Su, C.-H., Ryu, D., 2015. Multi-scale analysis of bias correction of soil moisture. Hydrol. Earth Syst. Sci. 19, 17-31. doi:10.5194/hess-19-17-2015

Su, C.-H., Ryu, D., Crow, W.T., Western, A.W., 2014. Beyond triple collocation: Applications to soil moisture monitoring. J. Geophys. Res. Atmos. 119, 6419-6439. doi:10.1002/2013JD021043 
982 Su, C.-H., Ryu, D., Young, R.I., Western, A.W., Wagner, W., 2013. Inter-comparison of 983 microwave satellite soil moisture retrievals over the Murrumbidgee Basin, southeast 984 Australia. Remote Sens. Environ. 134, 1-11. doi:10.1016/j.rse.2013.02.016

985 Vapnik, V.N., 1998. Statistical learning theory. Wiley.

986 Vapnik, V.N., Chervonenkis, A.Y., 1974. Theory of Pattern Recognition [in Russian]. Nauka, $987 \quad$ USSR.

988 Vladislavleva, E.J., Smits, G.F., den Hertog, D., 2009. Order of Nonlinearity as a Complexity 989 Measure for Models Generated by Symbolic Regression via Pareto Genetic Programming. 990 IEEE Trans. Evol. Comput. 13, 333-349. doi:10.1109/TEVC.2008.926486

$991 \mathrm{Xu}, \mathrm{S} .$, Chen, L., 2008. A novel approach for determining the optimal number of hidden layer 992 neurons for FNN's and its application in data mining.

993 Yilmaz, M.T., Crow, W.T., Anderson, M.C., Hain, C., 2012. An objective methodology for 994 merging satellite- and model-based soil moisture products. Water Resour. Res. 48, n/a-n/a. 995 doi:10.1029/2011WR011682

996 Yilmaz, M.T., Crow, W.T., Ryu, D., Yilmaz, M.T., Crow, W.T., Ryu, D., 2016. Impact of Model 997 Relative Accuracy in Framework of Rescaling Observations in Hydrological Data 998 Assimilation Studies. J. Hydrometeorol. 17, 2245-2257. doi:10.1175/JHM-D-15-0206.1

999 Yilmaz, M.T., Crow, W.T., Yilmaz, M.T., Crow, W.T., 2014. Evaluation of Assumptions in Soil 1000 Moisture Triple Collocation Analysis. J. Hydrometeorol. 15, 1293-1302. doi:10.1175/JHM$1001 \quad$ D-13-0158.1

1002 Yilmaz, M.T., Crow, W.T., Yilmaz, M.T., Crow, W.T., 2013. The Optimality of Potential 1003 Rescaling Approaches in Land Data Assimilation. J. Hydrometeorol. 14, 650-660. 1004 doi:10.1175/JHM-D-12-052.1 
1005

1006

1007

1008

1009

1010

1011

1012

1013

1014

1015

1016

1017

1018

1019

1020

1021

Yin, J., Zhan, X., Zheng, Y., Liu, J., Fang, L., Hain, C.R., Yin, J., Zhan, X., Zheng, Y., Liu, J., Fang, L., Hain, C.R., 2015. Enhancing Model Skill by Assimilating SMOPS Blended Soil Moisture Product into Noah Land Surface Model. J. Hydrometeorol. 16, 917-931. doi:10.1175/JHM-D-14-0070.1

Yin, J., Zhan, X., Zheng, Y., Liu, J., Hain, C.R., Fang, L., 2014. Impact of quality control of satellite soil moisture data on their assimilation into land surface model. Geophys. Res. Lett. 41, 7159-7166. doi:10.1002/2014GL060659

Zwieback, S., Dorigo, W., Wagner, W., 2013. Estimation of the temporal autocorrelation structure by the collocation technique with an emphasis on soil moisture studies. Hydrol. Sci. J. 58, 1729-1747. doi:10.1080/02626667.2013.839876

Zwieback, S., Scipal, K., Dorigo, W., Wagner, W., 2012. Structural and statistical properties of the collocation technique for error characterization. Nonlinear Process. Geophys. 19, 69-80. doi:10.5194/npg-19-69-2012

Zwieback, S., Su, C.-H., Gruber, A., Dorigo, W.A., Wagner, W., Zwieback, S., Su, C.-H., Gruber, A., Dorigo, W.A., Wagner, W., 2016. The Impact of Quadratic Nonlinear Relations between Soil Moisture Products on Uncertainty Estimates from Triple Collocation Analysis and Two Quadratic Extensions. J. Hydrometeorol. 17, 1725-1743. doi:10.1175/JHM-D-15-0213.1 


\section{List of Figure Captions}

1023 Figure 1: Schematic representations of the CDF and Copula based rescaling methods. The paths 1024 in the BADE and BCFE panels represent the $\mathrm{CDF}$ and Copula methods, respectively. $\mathrm{C}_{\mathrm{X} \mid \mathrm{Y}}=0.47$ 1025 is plotted with darker color in panel $\mathrm{C}$ to represent the best performing projection line of the 1026 Copula.

1027 Figure 2: Scatter plot of the Watershed average and LPRM soil moisture data over four 1028 watersheds. Original (unscaled) and rescaled data are given in the upper and middle rows, 1029 respectively; lagged unscaled LPRM vs unscaled LPRM are given in the lower row.

Figure 3: Performances of different rescaling methods during the training period were calculated

1031 as averages of the statistics given by the equations (16-18). The above values are obtained by 1032 averaging the results of two experiments by using different training and validation periods (i.e., 1033 the first and the last $75 \%$ of the data, respectively) and by averaging the results for four watersheds. 1034 Here, the olive green color represents copula, cyan represents ANN, dark green represents the 1035 remaining nonlinear methods, orange represents the linear methods that result in a correlation 1036 difference, and yellow represents the linear methods with no correlation change.

1037 Figure 4: Performances of different rescaling methods during the validation period. The above 1038 values are obtained by averaging the results of two experiments by using different validation 1039 periods.

1040 Figure 5: Added utility of the rescaling methods. 
Table 1: Parameters of the ANNs used in this study where identity is abbreviated as Id.

\begin{tabular}{|c|c|c|c|c|c|}
\hline \multirow[b]{2}{*}{$\mathbf{A N N}$} & \multicolumn{5}{|c|}{ Function Type } \\
\hline & Learning & Update & Output & & \\
\hline \multirow{4}{*}{ MLP } & \multirow{4}{*}{ Back-propagation } & \multirow{4}{*}{ Topological order } & \multirow{4}{*}{ Id. } & Input & Id. \\
\hline & & & & Hidden & Id. \\
\hline & & & & Context & -- \\
\hline & & & & Output & Id. \\
\hline \multirow{4}{*}{$\mathrm{RBF}$} & \multirow{4}{*}{ Back-propagation } & \multirow{4}{*}{ Topological order } & \multirow{4}{*}{ Id. } & Input & Id. \\
\hline & & & & Hidden & Gaussian \\
\hline & & & & Context & --- \\
\hline & & & & Output & Id.+bias \\
\hline \multirow{4}{*}{ ELMAN } & \multirow{4}{*}{ Back-propagation } & \multirow{4}{*}{ JE Order } & \multirow{4}{*}{ Id } & Input & Id. \\
\hline & & & & Hidden & Id. \\
\hline & & & & Context & Id. \\
\hline & & & & Output & Id. \\
\hline \multirow{4}{*}{ JORDAN } & \multirow{4}{*}{ Back-propagation } & \multirow{4}{*}{ JE Order } & \multirow{4}{*}{ Id. } & Input & Id. \\
\hline & & & & Hidden & Id. \\
\hline & & & & Context & Id. \\
\hline & & & & Output & Id. \\
\hline
\end{tabular}


1044 Table 2: Defined sets of GEN.

\begin{tabular}{|c|c|c|}
\hline \multirow{2}{*}{ Parameter } & \multicolumn{2}{|c|}{ Rescaling method } \\
\cline { 2 - 3 } & $X=f(Y)$ & GENL \\
\hline Causality relationship & "sin", "cos", "tan", "sqrt", "exp", "log", "+", "-", "*", "/", "^" \\
\hline Function set & $\frac{\left(Y^{*}-X\right)^{2}}{N}$ \\
\hline Fitness function & 100 \\
\hline Population size & Time (40 minutes) \\
\hline Stop condition & \multicolumn{2}{|c|}{} \\
\hline \multicolumn{2}{|c|}{ where $X, Y, Y_{\text {lag }}$, and $Y^{*}$ are the reference, unscaled, lagged form of unscaled, and rescaled } \\
\hline
\end{tabular}


1046 Table 3: Copula functions $\left(C_{Y X}\right)$, parameters $(P$ and $\theta)$, and characteristics used in this study. $F_{X}$ 1047 and $\mathrm{F}_{\mathrm{Y}}$ indicate $\mathrm{CDF}_{\mathrm{X}}$ and $\mathrm{CDF}_{\mathrm{Y}}$, respectively.

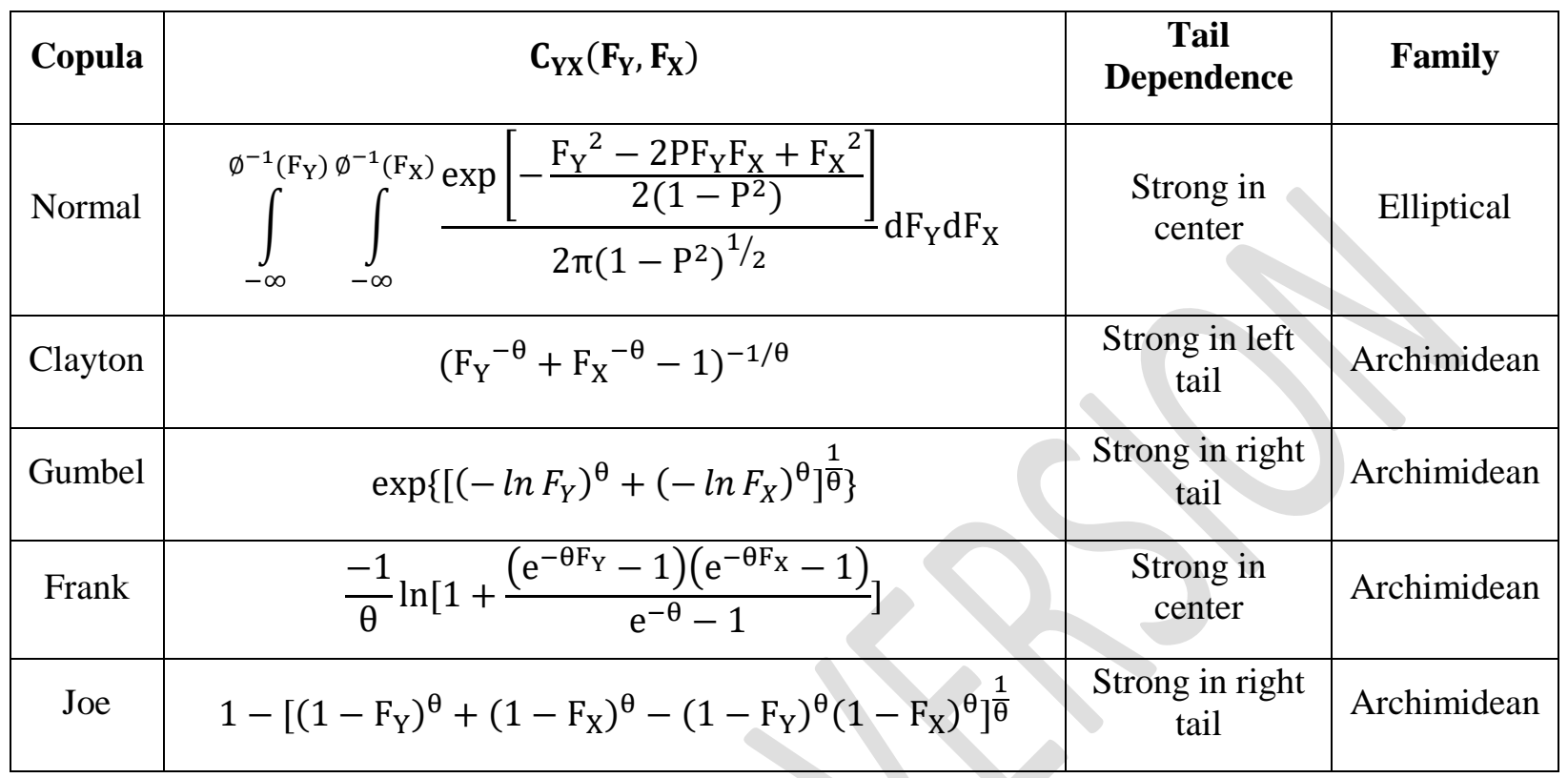


1050 Table 4: Statistics of the training and validation datasets for two experiments using the first and the $25 \%$ of the data as validation, respectively, and the remaining data as training.

\begin{tabular}{|c|c|c|c|c|c|c|c|c|c|}
\hline \multirow[t]{2}{*}{ Exp. } & \multirow[t]{2}{*}{ Dataset } & \multirow[t]{2}{*}{ Loc. } & \multirow{2}{*}{$\begin{array}{l}\text { Num. } \\
\text { avail. } \\
\text { points }\end{array}$} & \multicolumn{2}{|c|}{ Mean } & \multicolumn{2}{|c|}{$\begin{array}{l}\text { Standard } \\
\text { deviation }\end{array}$} & \multicolumn{2}{|c|}{$\begin{array}{c}\text { Lag1 } \\
\text { autocorrelation } \\
\text { of datasets } \\
\end{array}$} \\
\hline & & & & LPRM & In-situ & LPRM & In-situ & LPRM & In-situ \\
\hline \multirow{8}{*}{1} & \multirow{4}{*}{$\begin{array}{c}\text { Training } \\
\text { (last 75\%) }\end{array}$} & LR & 1193 & 0.311 & 0.105 & 0.099 & 0.046 & 0.784 & 0.819 \\
\hline & & $\mathrm{LW}$ & 1154 & 0.282 & 0.125 & 0.104 & 0.057 & 0.728 & 0.863 \\
\hline & & WG & 1239 & 0.18 & 0.046 & 0.074 & 0.022 & 0.801 & 0.889 \\
\hline & & $\mathrm{RC}$ & 1103 & 0.227 & 0.118 & 0.121 & 0.075 & 0.831 & 0.969 \\
\hline & \multirow{4}{*}{$\begin{array}{l}\text { Validation } \\
\text { (first 25\%) }\end{array}$} & LR & 396 & 0.331 & 0.109 & 0.098 & 0.044 & 0.757 & 0.805 \\
\hline & & LW & 383 & 0.286 & 0.118 & 0.099 & 0.052 & 0.686 & 0.751 \\
\hline & & WG & 411 & 0.176 & 0.045 & 0.083 & 0.021 & 0.785 & 0.849 \\
\hline & & $\mathrm{RC}$ & 366 & 0.232 & 0.107 & 0.104 & 0.072 & 0.778 & 0.974 \\
\hline \multirow{8}{*}{2} & \multirow{4}{*}{$\begin{array}{l}\text { Training } \\
\text { (first 75\%) }\end{array}$} & LR & 1192 & 0.316 & 0.106 & 0.1 & 0.046 & 0.757 & 0.826 \\
\hline & & $\mathrm{LW}$ & 1153 & 0.285 & 0.122 & 0.109 & 0.058 & 0.733 & 0.841 \\
\hline & & WG & 1238 & 0.18 & 0.044 & 0.077 & 0.022 & 0.789 & 0.879 \\
\hline & & $\mathrm{RC}$ & 1102 & 0.234 & 0.117 & 0.113 & 0.077 & 0.796 & 0.972 \\
\hline & \multirow{4}{*}{$\begin{array}{l}\text { Validation } \\
\text { (last 25\%) }\end{array}$} & LR & 397 & 0.314 & 0.105 & 0.095 & 0.043 & 0.855 & 0.784 \\
\hline & & $\mathrm{LW}$ & 384 & 0.276 & 0.127 & 0.077 & 0.049 & 0.628 & 0.828 \\
\hline & & WG & 412 & 0.175 & 0.048 & 0.076 & 0.02 & 0.814 & 0.881 \\
\hline & & $\mathrm{RC}$ & 367 & 0.21 & 0.109 & 0.129 & 0.067 & 0.866 & 0.963 \\
\hline
\end{tabular}


Table 5: Detailed performance of different rescaling methods during training and validation periods. Best statistics are shown in bold.

1054 The best performing method for training (Tr_best) and overall (best) are shown. The ones listed below are obtained by averaging the

\begin{tabular}{|c|c|c|c|c|c|c|c|c|c|c|c|c|c|c|c|c|c|c|c|}
\hline \multicolumn{2}{|c|}{ Statistic } & LOC & ORG & $\overline{\mathrm{AR}}$ & $\mathrm{CA}$ & EG1 & EG2 & REGL & EGL2 & MARS & MAR & $\mathrm{CDF}$ & GEN & GENL & SVM & SVML & MLP & MLPL & $\mathrm{RBF}$ \\
\hline \multirow{12}{*}{ 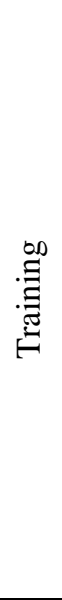 } & \multirow{4}{*}{ a } & LR & 0.567 & 0.567 & 0.567 & 0.567 & 0.580 & 0.576 & 0.586 & 0.600 & 0.618 & 0.577 & 0.595 & 0.608 & 0.602 & 0.617 & 0.579 & 0.589 & 0.580 \\
\hline & & LW & 0.514 & 0.514 & 0.514 & 0.514 & 0.536 & 0.531 & 0.551 & 0.602 & 0.630 & 0.566 & 0.570 & 0.635 & 0.604 & 0.674 & 0.552 & 0.569 & 0.536 \\
\hline & & WG & 0.696 & 0.696 & 0.696 & 0.696 & 0.708 & 0.712 & 0.733 & 0.734 & 0.772 & 0.721 & 0.730 & 0.761 & 0.730 & 0.773 & 0.709 & 0.742 & 0.708 \\
\hline & & $\mathrm{RC}$ & 0.698 & 0.698 & 0.698 & 0.698 & 0.709 & 0.732 & 0.734 & 0.727 & 0.759 & 0.687 & 0.727 & 0.753 & 0.727 & 0.765 & 0.721 & 0.750 & 0.709 \\
\hline & \multirow{4}{*}{$b^{\omega}$} & LR & 0.083 & 0.042 & 0.061 & 0.038 & 0.037 & 0.037 & 0.037 & 0.036 & 0.036 & 0.042 & 0.037 & 0.036 & 0.036 & 0.036 & 0.037 & 0.037 & 0.041 \\
\hline & & LW & 0.091 & 0.056 & 0.071 & 0.049 & 0.048 & 0.048 & 0.048 & 0.046 & 0.044 & 0.053 & 0.047 & 0.044 & 0.046 & 0.042 & 0.048 & 0.047 & 0.055 \\
\hline & & WG & 0.062 & 0.017 & 0.019 & 0.016 & 0.016 & 0.016 & 0.015 & 0.015 & 0.014 & 0.017 & 0.015 & 0.014 & 0.015 & 0.014 & 0.016 & 0.015 & 0.019 \\
\hline & & $\mathrm{RC}$ & 0.084 & 0.059 & 0.079 & 0.054 & 0.053 & 0.052 & 0.052 & 0.052 & 0.049 & 0.060 & 0.052 & 0.050 & 0.052 & 0.049 & 0.053 & 0.050 & 0.059 \\
\hline & \multirow{4}{*}{$\sum_{i}^{n}$} & LR & 0.208 & 0.000 & 0.000 & 0.000 & 0.000 & 0.000 & 0.000 & 0.000 & 0 & 0.000 & 0.000 & 0.000 & 0. & 03 & 01 & 000 & 0.031 \\
\hline & & LW & 0.160 & 0.000 & 0.000 & 0.000 & 0.000 & 0.000 & 0.000 & 0.000 & 0.000 & 0.000 & 0.001 & 0.001 & 0.006 & 0.004 & 0.001 & 0.000 & 0.018 \\
\hline & & WG & 0.135 & 0.000 & 0.000 & 0.000 & 0.000 & 0.000 & 0.000 & 0.000 & 0.000 & 0.000 & 0.000 & 0.000 & 0.002 & 0.001 & 0.000 & 0.000 & 0.006 \\
\hline & & $\mathrm{RC}$ & 0.113 & 0.000 & 0.000 & 0.000 & 0.000 & 0.000 & 0.000 & 0.000 & 0.000 & 0.000 & 0.001 & 0.000 & 0.003 & 0.003 & 0.000 & 0.001 & 0.018 \\
\hline \multirow{12}{*}{ 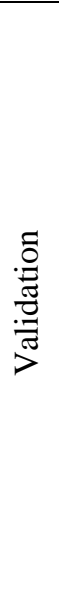 } & \multirow{4}{*}{0} & LR & 0.530 & 0.530 & 0.530 & 0.530 & 0.536 & 0.530 & 0.534 & 0.547 & 0.551 & 0.540 & 0.527 & 0.613 & 0.539 & 0.542 & 0.534 & 0.532 & 0.536 \\
\hline & & LW & 0.495 & 0.495 & 0.495 & 0.495 & 0.490 & 0.515 & 0.506 & 0.509 & 0.504 & 0.504 & 0.501 & 0.555 & 0.503 & 0.586 & 0.502 & 0.518 & 0.492 \\
\hline & & WG & 0.684 & 0.684 & 0.684 & 0.684 & 0.680 & 0.697 & 0.699 & 0.686 & 0.698 & 0.667 & 0.680 & 0.700 & 0.670 & 0.691 & 0.682 & 0.703 & 0.683 \\
\hline & & $\mathrm{RC}$ & 0.666 & 0.666 & 0.666 & 0.666 & 0.669 & 0.704 & 0.703 & 0.674 & 0.710 & 0.653 & 0.670 & 0.699 & 0.672 & 0.695 & 0.676 & 0.709 & 0.669 \\
\hline & \multirow{4}{*}{$0^{\omega}$} & LR & 0.082 & 0.043 & 0.061 & 0.037 & 0.037 & 0.037 & 0.037 & 0.037 & 0.037 & 0.043 & 0.038 & 0.034 & 0.037 & 0.037 & 0.037 & 0.037 & 0.041 \\
\hline & & LW & 0.077 & 0.049 & 0.060 & 0.043 & 0.044 & 0.043 & 0.043 & 0.044 & 0.044 & 0.054 & 0.044 & 0.042 & 0.045 & 0.041 & 0.043 & 0.043 & 0.048 \\
\hline & & WG & 0.067 & 0.018 & 0.020 & 0.015 & 0.015 & 0.015 & 0.015 & 0.015 & 0.015 & 0.017 & 0.015 & 0.015 & 0.016 & 0.015 & 0.015 & 0.015 & 0.018 \\
\hline & & $\mathrm{RC}$ & 0.088 & 0.061 & 0.084 & 0.053 & 0.053 & 0.050 & 0.051 & 0.052 & 0.050 & 0.061 & 0.053 & 0.052 & 0.053 & 0.052 & 0.052 & 0.050 & 0.054 \\
\hline & \multirow{4}{*}{$\sum_{<}^{n}$} & LR & 0.216 & 0.003 & 0.003 & 0.003 & 0.003 & 0.003 & 0.003 & 0.002 & 0.002 & 0.003 & 0.002 & 0.001 & 0.002 & 0.001 & 0.002 & 0.001 & 0.032 \\
\hline & & LW & 0.159 & 0.007 & 0.007 & 0.007 & 0.007 & 0.007 & 0.007 & 0.007 & 0.006 & 0.006 & 0.008 & 0.007 & 0.007 & 0.007 & 0.007 & 0.008 & 0.019 \\
\hline & & WG & 0.129 & 0.003 & 0.003 & 0.003 & 0.003 & 0.003 & 0.003 & 0.003 & 0.003 & 0.003 & 0.003 & 0.003 & 0.003 & 0.003 & 0.003 & 0.003 & 0.008 \\
\hline & & $\mathrm{RC}$ & 0.113 & 0.010 & 0.010 & 0.010 & 0.010 & 0.010 & 0.010 & 0.007 & 0.006 & 0.009 & 0.009 & 0.009 & 0.007 & 0.005 & 0.010 & 0.009 & 0.024 \\
\hline
\end{tabular}


Table 5, continuation.

\begin{tabular}{|c|c|c|c|c|c|c|c|c|c|c|c|c|c|c|c|c|c|c|c|}
\hline \multicolumn{2}{|c|}{ Statistic } & LOC & RBFL & ELM. & ELM.L & JOR. & JOR.L & NOR. & NOR.L & CLA. & CLA.L & GUM. & GUM.L & FRA. & FRA.L & $\mathrm{JOE}$ & JOEL & Tr_best & BEST \\
\hline \multirow{12}{*}{ 罗 } & \multirow{4}{*}{$a$} & LR & 0.585 & 0.595 & 0.601 & 0.591 & 0.597 & 0.585 & 0.591 & 0.581 & 0.558 & 0.566 & 0.546 & 0.594 & 0.562 & 0.517 & 0.517 & 0.618 & 0.618 \\
\hline & & LW & 0.558 & 0.583 & 0.592 & 0.556 & 0.585 & 0.561 & 0.570 & 0.560 & 0.519 & 0.550 & 0.523 & 0.581 & 0.531 & 0.520 & 0.511 & 0.674 & 0.674 \\
\hline & & WG & 0.740 & 0.747 & 0.748 & 0.726 & 0.737 & 0.722 & 0.746 & 0.631 & 0.655 & 0.721 & 0.727 & 0.725 & 0.727 & 0.720 & 0.727 & 0.773 & 0.773 \\
\hline & & $\mathrm{RC}$ & 0.741 & 0.850 & 0.844 & 0.829 & 0.826 & 0.708 & 0.741 & 0.725 & 0.759 & 0.697 & 0.746 & 0.709 & 0.751 & 0.673 & 0.734 & 0.850 & 0.850 \\
\hline & \multirow{4}{*}{$b^{\omega}$} & LR & 0.038 & 0.037 & 0.037 & 0.037 & 0.037 & 0.037 & 0.037 & 0.037 & 0.038 & 0.038 & 0.039 & 0.037 & 0.038 & 0.039 & 0.039 & 0.036 & 0.036 \\
\hline & & LW & 0.048 & 0.046 & 0.046 & 0.048 & 0.047 & 0.047 & 0.047 & 0.047 & 0.049 & 0.048 & 0.050 & 0.047 & 0.049 & 0.049 & 0.050 & 0.042 & 0.042 \\
\hline & & WG & 0.019 & 0.015 & 0.015 & 0.016 & 0.015 & 0.015 & 0.015 & 0.017 & 0.017 & 0.016 & 0.015 & 0.015 & 0.015 & 0.016 & 0.015 & 0.014 & 0.014 \\
\hline & & $\mathrm{RC}$ & 0.054 & 0.040 & 0.041 & 0.043 & 0.043 & 0.054 & 0.052 & 0.052 & 0.050 & 0.055 & 0.051 & 0.055 & 0.051 & 0.056 & 0.052 & 0.040 & 0.040 \\
\hline & \multirow{4}{*}{$\sum_{i}^{\infty}$} & LR & 0.024 & 0.003 & 0.005 & 0.006 & 0.007 & 0.000 & 0.000 & 0.017 & 0.023 & 0.001 & 0.004 & 0.001 & 0.004 & 0.000 & 0.002 & 0.000 & 0.000 \\
\hline & & LW & 0.023 & 0.008 & 0.007 & 0.006 & 0.009 & 0.000 & 0.002 & 0.025 & 0.029 & 0.000 & 0.013 & 0.000 & 0.036 & 0.001 & 0.005 & 0.000 & 0.000 \\
\hline & & WG & 0.038 & 0.002 & 0.001 & 0.004 & 0.003 & 0.000 & 0.000 & 0.000 & 0.001 & 0.000 & 0.000 & 0.000 & 0.000 & 0.000 & 0.000 & 0.000 & 0.000 \\
\hline & & $\mathrm{RC}$ & 0.015 & 0.004 & 0.001 & 0.003 & 0.003 & 0.001 & 0.001 & 0.000 & 0.001 & 0.007 & 0.004 & 0.001 & 0.003 & 0.017 & 0.013 & 0.000 & 0.000 \\
\hline \multirow{12}{*}{ 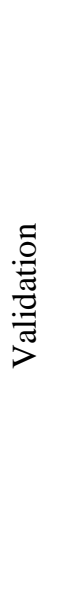 } & \multirow{4}{*}{ a } & LR & 0.532 & 0.535 & 0.533 & 0.535 & 0.537 & 0.536 & 0.534 & 0.532 & 0.503 & 0.524 & 0.496 & 0.536 & 0.505 & 0.484 & 0.468 & 0.551 & 0.613 \\
\hline & & LW & 0.510 & 0.535 & 0.543 & 0.514 & 0.538 & 0.502 & 0.512 & 0.493 & 0.445 & 0.499 & 0.462 & 0.511 & 0.459 & 0.475 & 0.458 & 0.586 & 0.586 \\
\hline & & WG & 0.706 & 0.713 & 0.711 & 0.700 & 0.698 & 0.678 & 0.688 & 0.638 & 0.608 & 0.671 & 0.646 & 0.684 & 0.651 & 0.662 & 0.635 & 0.691 & 0.713 \\
\hline & & $\mathrm{RC}$ & 0.705 & 0.801 & 0.785 & 0.779 & 0.792 & 0.666 & 0.702 & 0.673 & 0.696 & 0.659 & 0.692 & 0.661 & 0.688 & 0.641 & 0.682 & 0.801 & 0.801 \\
\hline & \multirow{4}{*}{$b^{\omega}$} & LR & 0.038 & 0.038 & 0.038 & 0.037 & 0.037 & 0.037 & 0.037 & 0.037 & 0.038 & 0.038 & 0.039 & 0.037 & 0.039 & 0.039 & 0.040 & 0.037 & 0.034 \\
\hline & & LW & 0.043 & 0.043 & 0.043 & 0.043 & 0.042 & 0.044 & 0.044 & 0.044 & 0.045 & 0.044 & 0.046 & 0.045 & 0.047 & 0.044 & 0.046 & 0.041 & 0.041 \\
\hline & & WG & 0.018 & 0.015 & 0.015 & 0.015 & 0.015 & 0.015 & 0.015 & 0.016 & 0.016 & 0.016 & 0.017 & 0.015 & 0.016 & 0.016 & 0.017 & 0.015 & 0.015 \\
\hline & & $\mathrm{RC}$ & 0.051 & 0.043 & 0.045 & 0.044 & 0.045 & 0.054 & 0.052 & 0.053 & 0.052 & 0.055 & 0.053 & 0.056 & 0.054 & 0.054 & 0.052 & 0.043 & 0.043 \\
\hline & \multirow{4}{*}{$\sum_{<}^{\infty}$} & LR & 0.026 & 0.004 & 0.007 & 0.004 & 0.006 & 0.002 & 0.002 & 0.016 & 0.021 & 0.001 & 0.006 & 0.002 & 0.006 & 0.001 & 0.003 & 0.003 & 0.001 \\
\hline & & LW & 0.024 & 0.016 & 0.016 & 0.007 & 0.011 & 0.008 & 0.007 & 0.022 & 0.028 & 0.009 & 0.021 & 0.007 & 0.035 & 0.010 & 0.005 & 0.007 & 0.005 \\
\hline & & WG & 0.036 & 0.004 & 0.004 & 0.004 & 0.004 & 0.003 & 0.003 & 0.002 & 0.002 & 0.003 & 0.003 & 0.002 & 0.002 & 0.003 & 0.003 & 0.003 & 0.002 \\
\hline & & $\mathrm{RC}$ & 0.021 & 0.005 & 0.006 & 0.007 & 0.008 & 0.008 & 0.007 & 0.009 & 0.007 & 0.012 & 0.009 & 0.007 & 0.008 & 0.022 & 0.018 & 0.010 & 0.005 \\
\hline
\end{tabular}


values indicate improvements, and negative values indicate degradation.

\begin{tabular}{|c|c|ccccccccc|}
\hline & & \multicolumn{7}{|c|}{ ADDED UTILITY OF METHODS AGAINST REG1 STATISTICS } \\
\hline Stat. & LOC & REGL2 & MARSL & CDF & GENL & SVML & ELMAN & NORMALL & Tr_Best & Best \\
\hline \multirow{5}{*}{$\rho$} & LR & 0.004 & 0.021 & 0.010 & 0.083 & 0.012 & 0.005 & 0.004 & 0.021 & 0.083 \\
& LW & 0.011 & 0.008 & 0.009 & 0.059 & 0.090 & 0.040 & 0.016 & 0.090 & 0.090 \\
& WG & 0.016 & 0.015 & -0.017 & 0.017 & 0.007 & 0.030 & 0.005 & 0.007 & 0.030 \\
& RC & 0.036 & 0.044 & -0.013 & 0.033 & 0.029 & 0.135 & 0.036 & 0.135 & 0.135 \\
\hline \multirow{6}{*}{$\sigma_{\varepsilon}$} & LR & 0.000 & 0.001 & -0.005 & 0.003 & 0.000 & -0.001 & 0.000 & 0.001 & 0.003 \\
& LW & 0.000 & -0.001 & -0.010 & 0.002 & 0.002 & 0.001 & -0.001 & 0.002 & 0.002 \\
& WG & 0.000 & 0.000 & -0.002 & 0.000 & 0.000 & 0.000 & 0.000 & 0.000 & 0.001 \\
& RC & 0.002 & 0.003 & -0.008 & 0.001 & 0.000 & 0.010 & 0.001 & 0.010 & 0.010 \\
\hline \multirow{5}{*}{$A M B$} & LR & 0.000 & 0.001 & 0.000 & 0.002 & 0.001 & -0.001 & 0.001 & 0.000 & 0.002 \\
& LW & 0.000 & 0.000 & 0.000 & -0.001 & -0.001 & -0.009 & 0.000 & 0.000 & 0.002 \\
& WG & 0.000 & 0.000 & 0.000 & 0.000 & 0.000 & -0.001 & -0.001 & 0.000 & 0.000 \\
& RC & 0.000 & 0.003 & 0.000 & 0.000 & 0.004 & 0.004 & 0.002 & 0.000 & 0.004 \\
\hline
\end{tabular}


1063 (e.g., $0.020 \rho$ value over LW is obtained as $\rho_{R E G L}-\rho_{\mathrm{REG} 1}$; and $0.086 \rho$ value over LR is obtained as $\rho_{G E N L}-\rho_{\mathrm{GEN}}$ using values given

in Table 5).

\begin{tabular}{|c|c|cccccc|}
\hline & & \multicolumn{5}{|c|}{ ADDED UTILITY OF LAGGED OBSERVATIONS } \\
\hline Stat. & LOC & REG1 & MARS & GEN & SVM & ELMAN & NORMAL \\
\hline \multirow{5}{*}{$\rho$} & LR & 0.000 & 0.004 & 0.086 & 0.003 & -0.002 & -0.002 \\
& LW & 0.020 & -0.005 & 0.053 & 0.083 & 0.008 & 0.010 \\
& WG & 0.013 & 0.013 & 0.020 & 0.021 & -0.002 & 0.010 \\
& RC & 0.038 & 0.035 & 0.029 & 0.023 & -0.016 & 0.036 \\
\hline \multirow{5}{*}{$\sigma_{\varepsilon}$} & LR & 0.000 & 0.000 & 0.003 & 0.000 & 0.000 & 0.000 \\
& LW & 0.001 & 0.000 & 0.002 & 0.004 & 0.000 & 0.000 \\
& WG & 0.000 & 0.000 & 0.000 & 0.001 & 0.000 & 0.000 \\
& RC & 0.002 & 0.002 & 0.002 & 0.001 & -0.002 & 0.002 \\
\hline \multirow{5}{*}{$A M B$} & LR & 0.000 & 0.000 & 0.001 & 0.000 & -0.003 & 0.000 \\
& LW & 0.000 & 0.000 & 0.000 & 0.000 & 0.000 & 0.001 \\
& WG & 0.000 & 0.000 & 0.000 & 0.000 & 0.000 & 0.000 \\
& RC & 0.000 & 0.001 & -0.001 & 0.001 & -0.001 & 0.000 \\
\hline
\end{tabular}


(A)

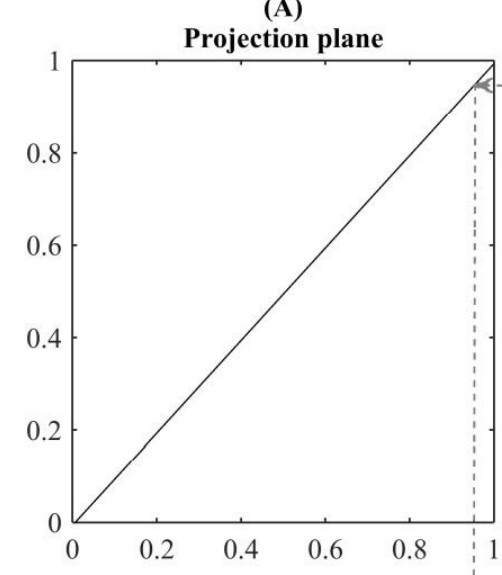

(D)

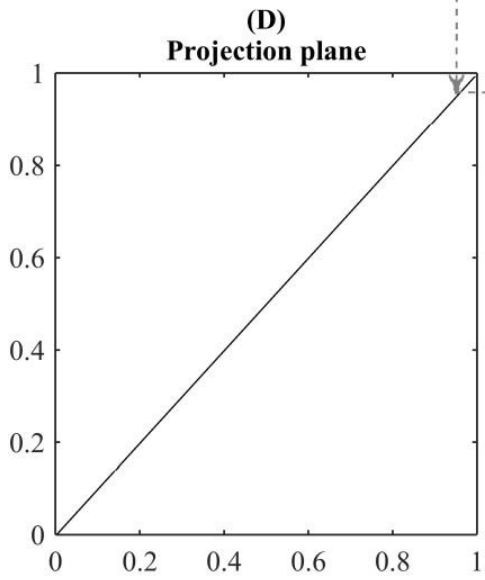

(B)

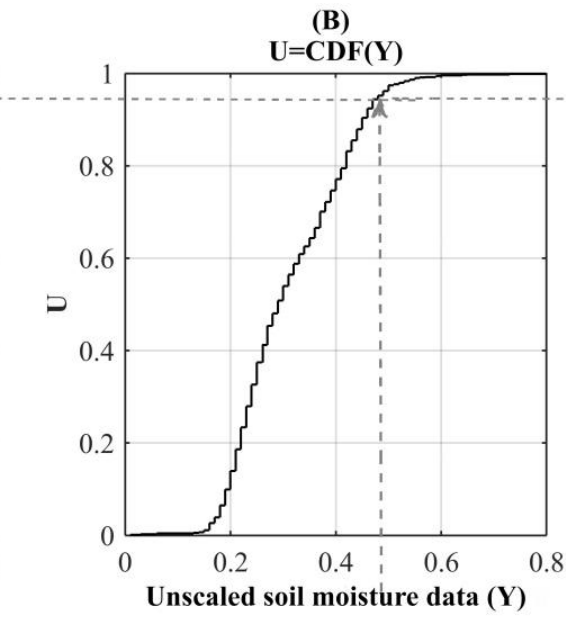

(E)

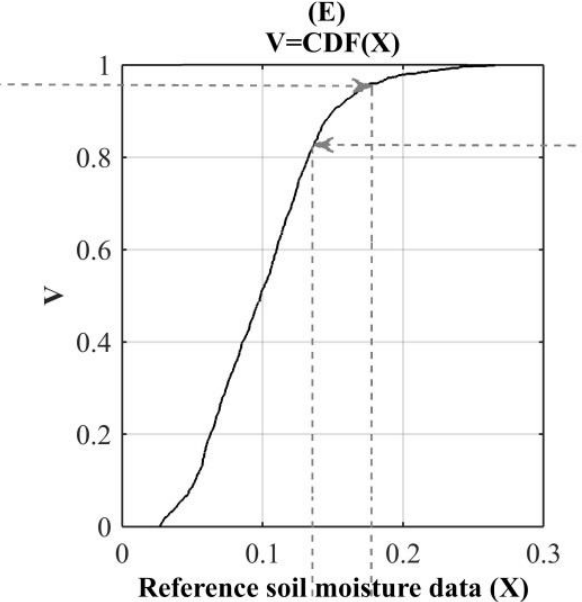

(C)

$\mathbf{C}(\mathbf{V} \mid \mathbf{U})$

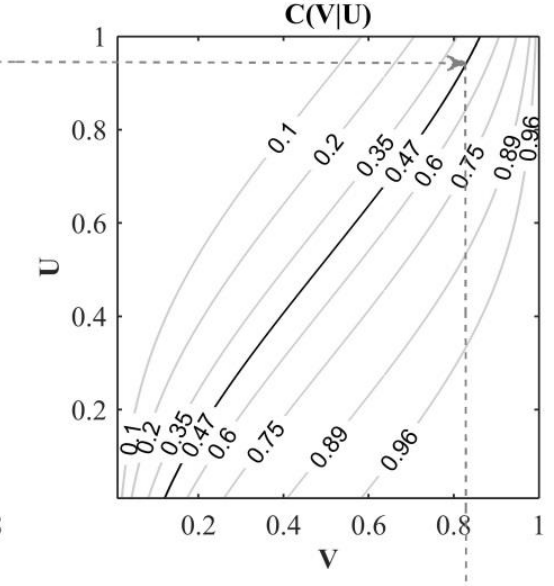

(F)

Projection plane

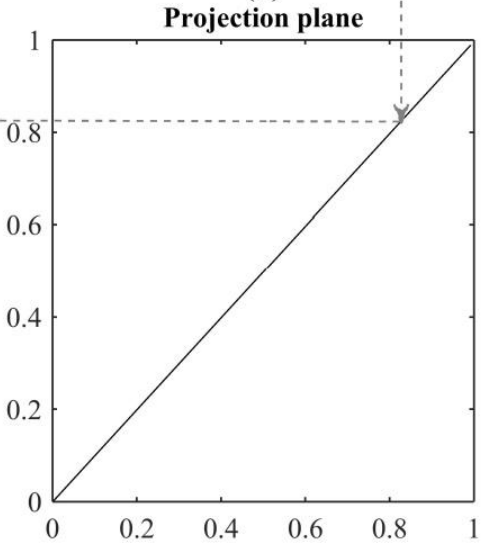

Rescaled soil moisture data by using copula approach

Rescaled soil moisture data by using CDF matching

1067 Figure 1: Schematic representations of the CDF and Copula based rescaling methods. The paths

1068 in the BADE and BCFE panels represent the CDF and Copula methods, respectively. $\mathrm{C}_{\mathrm{X} \mid \mathrm{Y}}=$

10690.47 is plotted with darker color in panel $\mathrm{C}$ to represent the best performing projection line of the 

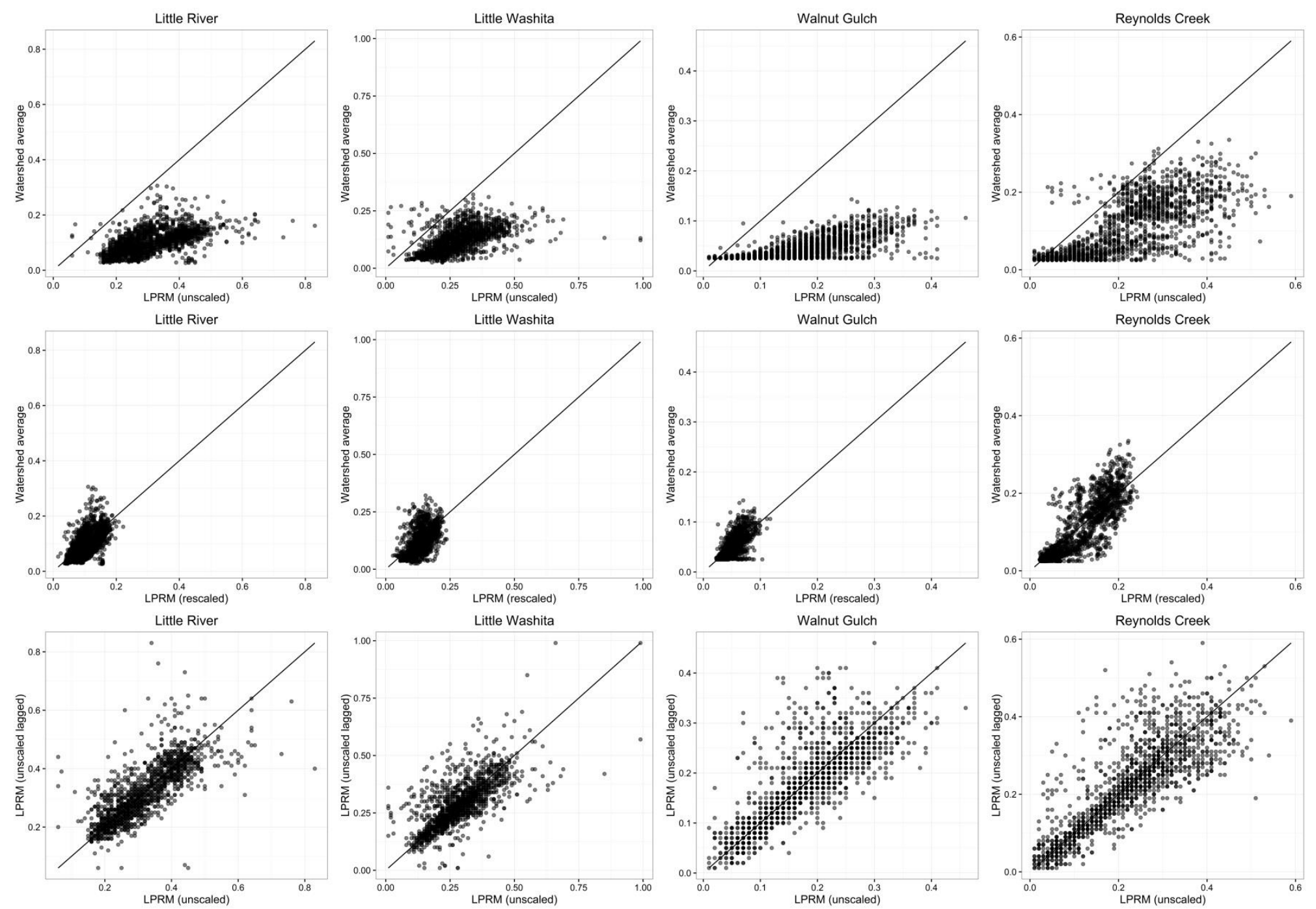

Figure 2: Scatter plot of the Watershed average and LPRM soil moisture data over four watersheds. Original (unscaled) and rescaled data are given in the upper and middle rows, respectively; lagged unscaled LPRM vs unscaled LPRM are given in the lower row. 

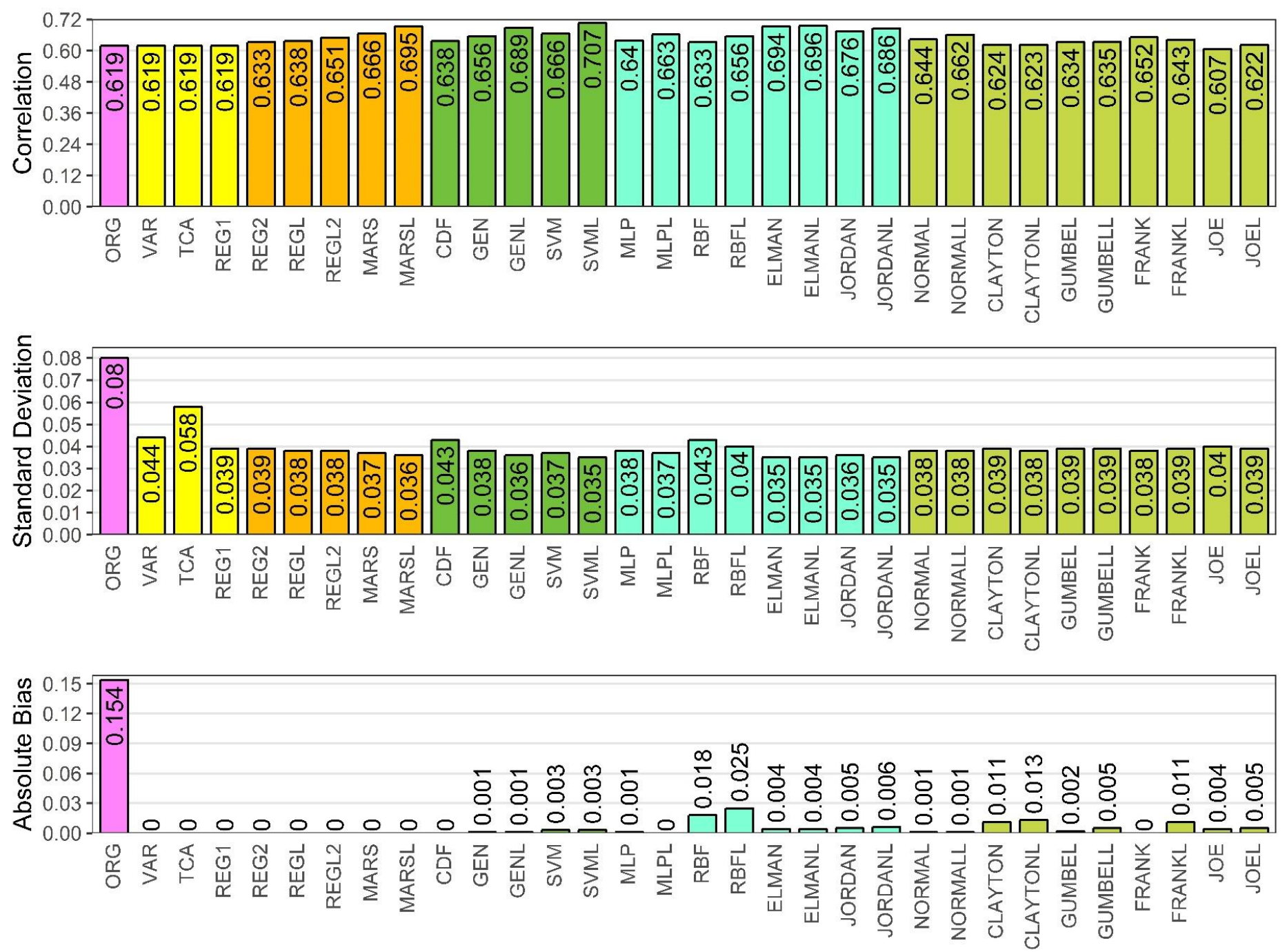

1075 Figure 3: Performances of different rescaling methods during the training period were calculated as averages of the statistics given by 
validation periods (i.e., the first and the last $75 \%$ of the data, respectively) and by averaging the results for four watersheds. Here, the olive green color represents copula, cyan represents ANN, dark green represents the remaining nonlinear methods, orange represents the linear methods that result in a correlation difference, and yellow represents the linear methods with no correlation change. 

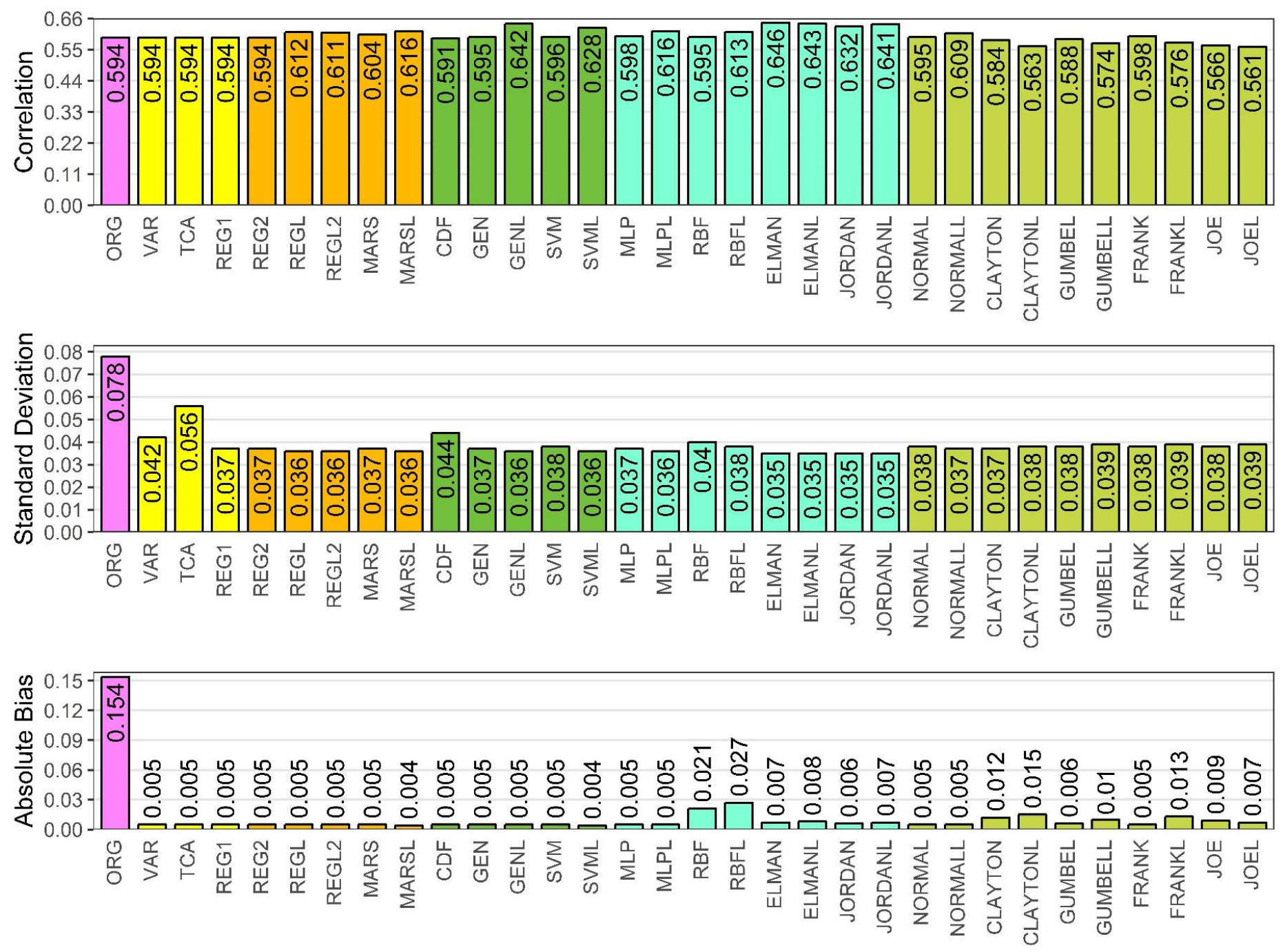

1080

1081 Figure 4: Performances of different rescaling methods during the validation period. The above values are obtained by averaging the 

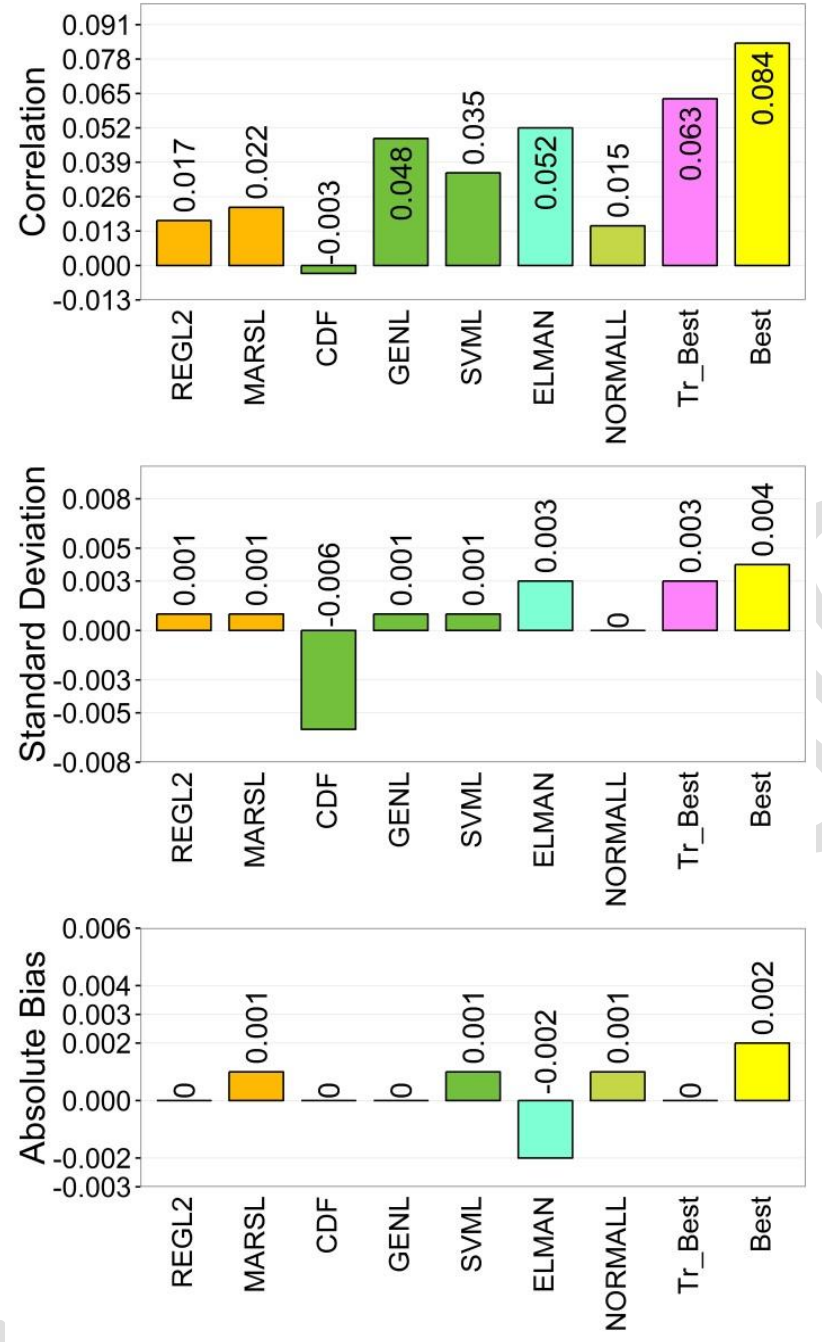

Figure 5: Added utility of the rescaling methods.

1085 